\title{
Does Discovery-Based Instruction Enhance Learning?
}

\author{
Louis Alfieri, Patricia J. Brooks, and \\ Naomi J. Aldrich \\ City University of New York
}

\author{
Harriet R. Tenenbaum \\ Kingston University
}

\begin{abstract}
Discovery learning approaches to education have recently come under scrutiny (Tobias \& Duffy, 2009), with many studies indicating limitations to discovery learning practices. Therefore, 2 meta-analyses were conducted using a sample of 164 studies: The 1st examined the effects of unassisted discovery learning versus explicit instruction, and the 2 nd examined the effects of enhanced and/or assisted discovery versus other types of instruction (e.g., explicit, unassisted discovery). Random effects analyses of 580 comparisons revealed that outcomes were favorable for explicit instruction when compared with unassisted discovery under most conditions $(d=-0.38,95 \%$ CI $[-.44,-.31])$. In contrast, analyses of 360 comparisons revealed that outcomes were favorable for enhanced discovery when compared with other forms of instruction $(d=0.30,95 \% \mathrm{CI}[.23, .36])$. The findings suggest that unassisted discovery does not benefit learners, whereas feedback, worked examples, scaffolding, and elicited explanations do.
\end{abstract}

Keywords: discovery learning, explicit instruction, scaffolding

Supplemental materials: http://dx.doi.org/10.1037/a0021017.supp

\begin{abstract}
The average student will be unable to recall most of the factual content of a typical lecture within fifteen minutes after the end of class. In contrast, interests, values, and cognitive skills are all likely to last longer, as are concepts and knowledge that students have acquired not by passively reading or listening to lectures but through their own mental efforts. (Bok, 2006, pp. 48-49)
\end{abstract}

Over the past several decades, conventional explicit instruction has been increasingly supplanted by approaches more closely aligned with constructivist concepts of exploration, discovery, and invention (i.e., discovery learning), at least in part because of an appreciation of which learning outcomes are most valuable (Bok, 2006). Allowing learners to interact with materials, manipulate variables, explore phenomena, and attempt to apply principles affords them with opportunities to notice patterns, discover underlying causalities, and learn in ways that are seemingly more robust. Such self-guided learning approaches, like Piaget (1952, 1965,

This article was published Online First November 15, 2010.

Louis Alfieri, Patricia J. Brooks, and Naomi J. Aldrich, Department of Psychology, College of Staten Island and the Graduate Center, City University of New York; Harriet R. Tenenbaum, School of Social Science, Kingston University, London, England.

The research reported is based on Louis Alfieri's doctoral dissertation submitted to the Doctoral Program in Cognition, Brain, and Behavior at the City University of New York. Preliminary results were presented at the biennial meeting of the Society for Research in Child Development, Denver, Colorado, April 2009. Purchase of software was supported by a Student-Faculty Research Technology Grant from the College of Staten Island/City University of New York awarded to Patricia J. Brooks.

Correspondence concerning this article should be addressed to Louis Alfieri or Patricia J. Brooks, Department of Psychology, College of Staten Island/City University of New York, 2800 Victory Boulevard, 4S-103, Staten Island, NY 10314. E-mail: alfieri_psych@hotmail.com or patricia.brooks@csi.cuny.edu
1980) proposed, posit the child/learner at the center of the learning process as he/she attempts to make sense of the world. From an ecological perspective, people learn many complex skills without formal instruction through participation in daily activities and observation of others (Rogoff, 1990). Indeed, in cultures without institutionalized formal education, complex skills and modes of thought are learned in the absence of explicit, verbal teaching. Nonetheless, debate remains concerning the limitations of discovery learning (Bruner, 1961; Kirschner, Sweller, \& Clark, 2006; Klahr \& Nigam, 2004; Mayer, 2004; Sweller, Kirschner, \& Clark, 2007; Tobias \& Duffy, 2009). Pedagogical and cognitive concerns have led to some disagreement as to what constitutes effective discovery learning methods and how and when such methods should be applied. Two recent review articles (Kirschner et al., 2006; Mayer, 2004) have outlined some of the problems associated with various discovery-based instructional methods; however, no systematic meta-analysis has been conducted on this literature. For instance, it is unclear (a) whether the process of how to discover information on one's own needs to be taught to learners (Ausubel, 1964; Bruner, 1961), (b) to what extent discovery tasks should be structured (Mayer, 2004), (c) which types of tasks are within the realm of discovery methods (Klahr \& Nigam, 2004), and (d) whether the working memory demands of discovery-learning situations jeopardize the efficacy of the instruction (Kirschner et al., 2006). In the current meta-analyses, we evaluate these concerns.

\section{A Definition of Discovery Learning}

Before proceeding, it is necessary to reflect on the wide range of instructional conditions that have been included under the rubric of discovery learning. Because methods employing discovery learning involve a wide variety of intended accomplishments during the acquisition of the target content, a definition of discovery learning is needed. However, there is a myriad of discovery-based learning approaches presented within the literature without a precise defi- 
nition (Klahr \& Nigam, 2004). Learning tasks considered to be within the realm of discovery learning range from implicit pattern detection (Destrebecqz, 2004; Jiménez, Méndez, \& Cleeremans, 1996) to the elicitation of explanations (Chi, de Leeuw, Chiu, \& LaVancher, 1994; Rittle-Johnson, 2006), and from working through manuals (Lazonder \& van der Meij, 1993) to conducting simulations (Stark, Gruber, Renkl, \& Mandl, 1998). What exactly constitutes a discovery-learning situation is seemingly yet undetermined by the field as a whole. At times, the discovery condition seems less influenced by the learning methods and more by the comparison methods. That is, when a comparison group has received some greater amount of explicit instruction, whatever the type or degree, investigators often refer to the other group as a discovery group because it has been assisted less during the learning process.

A review of the literature suggests that discovery learning occurs whenever the learner is not provided with the target information or conceptual understanding and must find it independently and with only the provided materials. Within discovery-learning methods, there is an opportunity to provide the learners with intensive or, conversely, minimal guidance, and both types can take many forms (e.g., manuals, simulations, feedback, example problems). The extent to which the learner is provided with assistance seems to be contingent upon the difficulty in discovering the target information with less assistance and also on the instructional methodologies to which it is being compared. Common to all of the literature, however, is that the target information must be discovered by the learner within the confines of the task and its material.

\section{Concerns and Warnings About Discovery Learning}

As early as the 1950s, research had begun to investigate the effects of discovery learning methods in comparison with other forms of instruction. Bruner (1961) and others (Ausubel, 1964; Craig, 1965; Guthrie, 1967; Kagan, 1966; Kendler, 1966; Kersh, 1958, 1962; Ray, 1961; Scandura, 1964; Wittrock, 1963; Worthen, 1968) advocated learning situations that elicited explanations or self-guided comprehension from learners and that provided opportunities for learners to gain insights into their domains of study. Bruner emphasized that such discovery-based learning could enhance the entire learning experience while also cautioning that such discovery could not be made a priori or without at least some base of knowledge in the domain in question. Although Bruner's article has often been cited as support for discovery learning, many have seemingly ignored his warnings (i.e., the limitations of such an approach to instruction).

Recently, Mayer (2004) argued that pure, unassisted discoverylearning practices should be abandoned because of a lack of evidence that such practices improve learning outcomes. Through a review of the literature, he illustrated that unassisted discoverylearning tasks did not help learners discover problem-solving rules, conservation strategies, or programming concepts. Mayer emphasized that although constructivist-based approaches might be beneficial to learning under some circumstances, unassisted discovery learning does not seem advantageous because of its lack of structure. He further emphasized that unassisted discovery-learning tasks involving hands-on activities, even with large group discus- sions, do not guarantee that learners will understand the task or that they will come into contact with the to-be-learned material.

Furthermore, Klahr (2009) and others (Clark, 2009; Mayer, 2009; Rosenshine, 2009; Sweller, 2009) have emphasized that there are times when more explicit instruction or at least directive guidance is optimal. Although Klahr's concerns were in teaching the control of variables strategy (CVS), his arguments regarding instructional times, feedback, instructional sequences, and generalization of skills emphasize that in certain situations some amount of direct instruction is advantageous. In the case of CVS, Klahr has argued that learners might have difficulty arriving at the proper strategy of holding all other variables constant while manipulating only one. He has explained that such scientific problem solving, although commonplace to cognitive scientists who have a great understanding of the cognitive processes involved in such a task, might not arise simply by asking novice learners to figure out how to use the provided materials. Even if such a strategy is reached and implemented by learners, it might require a great deal of time, which could have been saved through direct teaching of the CVS. Klahr has suggested that perhaps it would be more time efficient to instruct learners directly on how to implement CVS and then to give them ample opportunities to practice it. Moreover, direct instruction in CVS learning tasks might be necessary because the manipulation of the materials alone does not provide sufficient feedback; learners are not presented with any indication of shortcomings in their strategies if they fail to manipulate only one variable at a time. By explicitly teaching learners about the cognitive processes involved in problem solving and the ways in which scientists go about uncovering causal factors, Klahr has argued that learners will be empowered to use these skills and that their understandings can be strengthened by activities that afford them with opportunities to practice these skills in a domain of interest and, consequently, to discover knowledge in that domain by doing so.

Similarly, Sweller et al. (2007) have emphasized the usefulness of worked examples over other forms of instruction. They have suggested that instructors should provide a complete problem solution for learners to study and practice for themselves. They have argued that such a learning technique would be superior to less guided forms of instruction because of the limited capacity of working memory. Although that claim is addressed in a subsequent section, it is noteworthy that the encouragement to use worked examples is similar to Klahr's (2009) suggestion to demonstrate CVS to learners and then to provide them with opportunities for practice.

\section{Direct Instruction and Construction}

The example of teaching CVS directly, as described by Klahr (2009), illustrates the variability of what is meant by direct instruction. Klahr did not suggest lecture-type instructional situations. Instead, he suggested some degree of guidance as to what learners should expect as evidence of successful learning and then giving them opportunities to practice using such skills on their own. This suggestion is not unique to Klahr but has been raised by a number of researchers on both sides of the debate (Clark, 2009; Herman \& Gomez, 2009; Kintsch, 2009; Pea, 2004; Rosenshine, 2009; Sweller et al., 2007; Wise \& O’Neill, 2009). Although Klahr's arguments might not be appropriate in all domains or for 
all learning tasks, his suggestions to employ direct instruction as a basis for subsequent discovery address some of the concerns that discovery-learning tasks lack structure and, therefore, overwhelm the learner's cognitive workspace.

Note also that Klahr (2009) did not position direct instruction in opposition to constructivism in that he asserted that learners should be provided with opportunities to manipulate materials directly. In a way, Klahr might be helping to unite constructivism and more direct forms of instruction by emphasizing that sometimes, as in the case of CVS, direct instruction will facilitate constructivist learning by reducing task ambiguities and learning times while improving process comprehension and potential generalization. More generally, Klahr's suggestions to provide some amount of direct instruction might reduce the cognitive demands of discovery tasks by familiarizing learners with the processes involved, as we discuss below.

\section{Cognitive Factors}

At the most basic level, memory is enhanced when learning materials are generated by the learner in some way; this is commonly referred to as the generation effect (Slamecka \& Graf, 1978). The robust effect is that materials generated or even merely completed by learners are remembered more often and/or in greater detail than materials provided by an instructor. This effect is often presented as evidence that discovery learning is efficacious because such learning involves the discovery and generation of general principles or explanations of domain-specific patterns after discovering such on one's own (Chi et al., 1994; Crowley \& Siegler, 1999; Schwartz \& Bransford, 1998). Therefore, the expectation is that discovery-based approaches, because of the requirement that learners construct their own understandings and consequently the content, should yield greater learning, comprehension, and/or retention. Note, however, that the majority of tasks used in the generation effect are simple (e.g., recalling a word), unlike much of the research on discovery learning, which involves more involved tasks such as CVS.

\section{Cognitive Load Theory and Concerns}

With regard to the cognitive processes involved in discovery learning, Mayer (2003) emphasized that discovery-based pedagogy works best in promoting meaningful learning when the learner strives to make sense of the presented materials by selecting relevant incoming information, organizing it into a coherent structure, and integrating it with other organized knowledge. However, to select, organize, and integrate high-level information in a task-appropriate way is quite demanding of learners. Both Sweller (1988) and Rittle-Johnson (2006) have emphasized that because discovery learning relies on an extensive search through problemsolving space, the process taxes learners' limited working-memory capacity and frequently does not lead to learning. In addition, learners need the ability to monitor their own processes of attention to relevant information (Case, 1998; Kirschner et al., 2006). This would seem to require learners to have considerable metacognitive skills, and it is unlikely that all learners, in particular children, would have such skills (Dewey, 1910; Flavell, 2000; Kuhn \& Dean, 2004). Thus, learning by discovery seems to require a greater number of mental operations, as well as better executive control of attention, in comparison with learning under a more directive approach. Furthermore, cognitive load theory suggests that the exploration of complex phenomena or learning domains imposes heavy loads on working memory detrimental to learning (Chandler \& Sweller, 1991; Kirschner et al., 2006; Paas, Renkl, \& Sweller, 2003; Sweller, 1988, 1994).

\section{Predictions}

The cognitive demands involved in discovery-based pedagogies make them seem daunting and implicate a number of predictions. For example, young learners (i.e., children) might be least likely to benefit from such methods (Case, 1998; Kirschner et al., 2006; Mayer, 2004) compared with their older counterparts. Younger learners would have comparatively limited amounts of organized, preexisting knowledge and schemas to be able to integrate new information effectively. Children have more limited working memory capacities (Kirschner et al., 2006) and experiences in using the cognitive processes outlined by Mayer (2004) and others. Furthermore, they lack the metacognitive skills required to monitor their cognitive processes (Flavell, 2000; Kuhn \& Dean, 2004).

\section{Issues of Guidance Within the Debate Between Constructivist Instruction and Explicit Instruction}

Of course constructivism does not assert that all learning should be unaided (Hmelo-Silver, Duncan, \& Chinn, 2007; Schmidt, Loyens, van Gog, \& Paas, 2007; Spiro \& DeSchryver, 2009). Nonetheless, although guidance has been an important component of instruction on both sides of the debate concerning constructivist instruction (Tobias \& Duffy, 2009), there remains a remarkable number of discovery-based instructional tasks that are largely unassisted. As Duffy (2009) has explained, explicit instruction advocates seemingly intend for their students to reach their learning objectives in the most efficient ways possible, whereas constructivism advocates emphasize learners' motivation and tend to provide guidance or feedback only when learners prompt it through inquiry.

An illustration of these different standpoints can be found in the correspondence of Fletcher (2009) with Schwartz, Lindgren, and Lewis (2009), in which he claimed that more direct forms of instruction work better when learners have little prior knowledge. In response, Schwartz et al. provided the example of children having to learn to tie their shoes without having ever seen a shoe before. They argued that in such a case, hands-on exploration would be optimal so that the children could familiarize themselves with the layout of the shoe, its laces, and so forth. However, because these children have never seen a shoe before, one might argue just the opposite: to understand the utility of having shoes tied, children should be provided explicitly with the task objective and a means for achieving the goal.

Because their intentions and learning objectives are different (Schwartz et al., 2009), the ways in which the explicit instruction and constructivism camps understand learning situations are different (Duffy, 2009; Kuhn, 2007). However, both camps have tended to include some forms of guidance within instructional designs (Tobias \& Duffy, 2009), and in the current analyses, it is our intention to determine which types of enhancement are best. Enhanced-discovery methods include a number of techniques from 
feedback to scaffolding (Rosenshine, 2009), and many studies have been conducted that have employed different forms and degrees of guidance during learning tasks.

We conducted two meta-analyses because of the ambiguity within the literature as to what constitutes a discovery-learning method and how and when such methods should be applied. In the first meta-analysis, we compared unassisted discovery-learning methods (e.g., teaching oneself, completing practice problems, conducting simulations) with more explicit instruction. In the second meta-analysis, we compared enhanced discovery-learning methods (e.g., guided discovery, elicited self-explanation) with a variety of instructional conditions, including unassisted discovery as well as explicit instruction.

\section{Method}

\section{Literature Search}

Articles examining different types of discovery learning were identified through a variety of sources. The majority of the articles were identified using PsycINFO, ERIC, and Dissertation Abstracts International computerized literature searches. Studies were also identified from citations in articles. The selection criterion for the first meta-analysis was that studies had to test directly for differences between an explicit training or instruction condition (explicit) and a condition in which unassisted discovery learning occurred, which was operationally defined as being provided with no guidance or feedback during the learning task. The selection criterion for the second meta-analysis was that the study included a condition in which discovery learning was operationally defined as being provided with guidance in the learning task, along with a comparison condition. In other words, in the first meta-analysis, we evaluated the effects of unassisted discovery-learning conditions versus explicit instruction, whereas in the second metaanalysis, we evaluated the effects of guided or enhanced discovery-learning conditions versus other forms of instruction.

Exclusion criteria precluded the use of several potentially relevant studies. First, articles with unclear statistical information or those that were based on only qualitative data alone were not included. Because we did not want to perform simply a sign test, we did not include articles that did not provide useable statistical information. However, before discarding any articles, authors were contacted for information that could be included in the metaanalysis. Second, articles needed to include comparable conditions that consistently differed in the type of instruction. Those comparing conditions that were fundamentally different or that were equivocated prior to testing could not be included.

\section{Units of Analysis and Data Sets}

As the unit of analysis, group samples of studies and comparisons were considered separately. Studies as a unit of analysis referred to individual experiments with different participants. Studies, thus, treat multiple experiments reported within a single article as separate studies if they involved different participants. Comparisons were also used as a unit of analysis. Analysis at the level of comparisons refers to counting each individual statistical comparison as an independent contribution. Articles that run many comparisons have more weight in the overall computation of the effect than those that run fewer. Because many potentially moderating variables differ between comparisons, only one moderator (i.e., publication rank) could be tested using studies as the unit of analysis. All other moderators were analyzed at the level of comparisons. Although multiple comparisons reported for a single sample violate assumptions of independence, analysis at this level was required to test for effects of moderating variables.

\section{Variables Coded From Studies as Possible Moderators for the Meta-Analyses}

Six moderators were used for blocking purposes in both metaanalyses. See Table 1 for the complete listing of the categories of each moderator. Publication rank was the first moderator to be considered. Studies from top-ranked journals were compared with studies from other sources. Top-ranked journals included any journal with an impact factor $>1.5$ on the basis of the 2001 listings of impact factors. All other journal publications that ranked below 1.5 were coded as second-tier journal articles. Studies published in book chapters were coded separately, and studies included in dissertations or unpublished works (e.g., conference poster presen-

Table 1

Categories of Each Moderator

\begin{tabular}{|c|c|}
\hline Moderator & Categories \\
\hline \multirow[t]{4}{*}{ Publication rank } & Journal impact factor $>1.5$ \\
\hline & Journal impact factor $<1.5$ \\
\hline & Book chapters \\
\hline & Unpublished/dissertations \\
\hline \multirow[t]{6}{*}{ Domain } & Math/numbers \\
\hline & Computer skills \\
\hline & Science \\
\hline & Problem solving \\
\hline & Physical/motor skills \\
\hline & Verbal/social skills \\
\hline \multirow[t]{3}{*}{ Age } & Children: $<12$ years of age \\
\hline & Adolescents: between 12 and 18 years of age \\
\hline & Adults: $>18$ years of age \\
\hline \multirow[t]{6}{*}{ Dependent measure } & $\begin{array}{l}\text { All post-tests scores, error rates, rates of error } \\
\text { detection }\end{array}$ \\
\hline & Acquisition scores \\
\hline & Reaction time scores \\
\hline & Self-ratings \\
\hline & Peer ratings \\
\hline & Mental effort/load ratings \\
\hline \multirow[t]{5}{*}{ Unassisted discovery } & Unassisted, teaching oneself, practice problems \\
\hline & Invention \\
\hline & $\begin{array}{l}\text { Other: matched guidance/probes in both } \\
\text { discovery and comparison conditions }\end{array}$ \\
\hline & Simulation \\
\hline & Work with a naïve peer \\
\hline \multirow[t]{3}{*}{ Enhanced discovery } & Generation \\
\hline & Elicited explanation \\
\hline & Guided discovery \\
\hline \multirow{8}{*}{$\begin{array}{c}\text { Comparison } \\
\text { condition }\end{array}$} & Direct teaching \\
\hline & Feedback \\
\hline & Worked examples with solutions provided \\
\hline & Baseline \\
\hline & Unassisted: no exposure nor explanation \\
\hline & $\begin{array}{l}\text { Enhanced: unassisted discovery or textbook } \\
\text { only }\end{array}$ \\
\hline & Explanations provided \\
\hline & Other: study-specific condition \\
\hline
\end{tabular}


tations) were coded separately. Although impact factors have increased in the intervening years, the rank ordering of journals has changed very little.

Second, the domains of the studies were considered. The following domains were coded for: (a) math/numbers, (b) computer skills, (c) science, (d) problem solving, (e) physical/motor skills, and (f) verbal/social skills. Next, the ages of participants were coded. Participants were considered children if they were 12 years of age or younger, adolescents if they were between 13 and 17 years of age, and adults if they were 18 years of age or older. If the same statistical test included a range of ages, the mean age of the sample was used for coding purposes. If the exact ages were not provided but their grade levels were, participants were coded as children through sixth grade, as adolescents from seventh to 12 th grades, and as adults thereafter.

The dependent variable was the next moderator considered. Post-tests were assessments administered after the learning phases. These scores included a variety of assessment types from pure post-test scores to improvement scores, with previous assessments used as baseline measures on tasks ranging from error detection/ correction to content recall, depending on the domain in question. Acquisition scores included measurements of learning, success, or failed attempts/errors during the learning phases. Reaction time scores reflected the amount of time employed to arrive at the target answer. Self-ratings included ratings by learners of their own motivation levels, competencies, or other aspects of the learning tasks. Peer ratings included ratings by observing peers or other learners in regard to the learners' competencies or other aspects of the learning tasks. Mental effort reflected scores determined by the experimenters who calculated mental load reflective of the amount of information being considered, the number of variables to be manipulated, the number of possible solutions, and so forth that learners had to manage to complete the task successfully.

The fifth moderator to be considered was the type of discovery learning condition employed. The types of discovery learning for the first meta-analysis, comparing explicit with unassisted discovery learning conditions, included the following: unassisted, invention, matched probes, simulation, and work with a naïve peer. The unassisted conditions included the learners' investigation or manipulation of relevant materials without guidance, the learners teaching themselves through trial-and-error or some other means, and/or the learners attempting practice problems. The invention conditions included tasks that required learners to invent their own strategies or to design their own experiments. The matched probes conditions included hints in the form of probe questions or minimal types of feedback, which were provided to learners in both the unassisted-discovery conditions and the explicit-instruction conditions. For example, Morton, Trehub, and Zelazo (2003, Experiment 2) asked 6-year-old children to decide whether a disembodied voice was happy or sad and either provided them with uninformative general instructions (i.e., unassisted discoverymatched probes condition) or explicit instructions to attend to the tone of voice (i.e., comparison condition-feedback condition). As both groups of children were provided with feedback as to whether they were correct or incorrect, this minimal form of feedback was considered to be a matched probe. The simulation conditions included computer-generated simulations that required learners to manipulate components or to engage in some type of practice to foster comprehension. The work with a naïve peer conditions were those that paired learners with novice or equal learning partners.

The types of discovery learning for the second meta-analysis were considered to be enhanced forms of discovery learning methods and included generation, elicited explanations, and guided discovery conditions. Generation conditions required learners to generate rules, strategies, images, or answers to experimenters' questions. Elicited explanation conditions required that learners explain some aspect of the target task or target material, either to themselves or to the experimenters. The guided discovery conditions involved either some form of instructional guidance (i.e., scaffolding) or regular feedback to assist the learner at each stage of the learning tasks.

Lastly, the type of comparison condition was investigated. $\mathrm{Di}$ rect teaching conditions included the explicit teaching of strategies, procedures, concepts, or rules in the form of formal lectures, models, demonstrations, and so forth and/or structured problem solving. Feedback conditions took priority over other coding and included any instructional design in which experimenters responded to learners' progress to provide hints, cues, or objectives. Conditions of worked examples included provided solutions to problems similar to the targets. Baseline conditions included designs in which learners were not given the basic instructions available to the discovery group, learners were asked to complete an unrelated task that required as much time as the discovery group's intervention, or learners were asked to complete pre- and post-tests only with a time interval matched to the discovery group's. The explanations provided conditions were those in which explanations were provided to learners about the target material or the goal task. Other conditions included conditions (i.e., one comparison in the analysis of unassisted discovery and two comparisons in the analysis of enhanced discovery) that were largely experiment-specific in that the condition could not fairly be categorized as any other code because the instructional change involved only a minimal change in design.

Comparison conditions for the second meta-analysis included all of the above except for feedback conditions. Also, the baseline conditions for the second meta-analysis differed slightly in that such conditions in the second meta-analysis more often involved designs in which learners were asked to teach themselves either through physical manipulations or through textbook learning (i.e., similar to the unassisted-discovery conditions of the first metaanalysis), and designs in which only pre- and post-tests were administered with interceding time intervals matched to the discovery group.

\section{Reliability on Moderators}

Coding for moderators was accomplished with recommendations from the four authors who decided on moderator codes to include the range of conditions, completely and yet concisely. Reliability on all moderators for both meta-analyses was found to be consistently high leading to an overall kappa of .87. All disagreements were resolved through a discussion of how best to classify the variable in question both within the context of the study and the purposes of analysis. 


\section{Computation and Analysis of Effect Sizes}

Given the great variety of discovery learning designs and the variety of undetermined factors involved in any potential effects, a random effects model was used in all analyses in the Comprehensive Meta-Analysis Version 2 (CMA) program (Borenstein, Hedges, Higgins, \& Rothstein, 2005). A random effects model is appropriate when participant samples and intervention factors cannot be presumed to be functionally equivalent. Consequently, effect sizes cannot be presumed to share a common effect size because they may differ because of any one or a number of different factors between studies. However, in the current metaanalyses, we report overall results from both fixed and random effects models and then present subsequent results only from the random effects model.

Effect sizes. Computation formulae included within the CMA program allowed for direct entry of group statistics to calculate effect sizes for each test-by-test comparison. When the only statistics available were $F$ values and group means, DSTAT (Johnson, 1993) allowed us to convert those statistics to a common metric, $g$, which represents the difference in standard deviation units. More specifically, $g$ is computed by calculating the difference of the two means divided by the pooled standard deviation of the two samples (e.g., the difference between two groups' mean reaction times, divided by the pooled standard deviation). Those $g$ scores and other group statistics were then entered into the CMA program. For analyses at the level of studies, overall $g$ statistics were calculated in DSTAT before entry into the CMA program.

Because $g$ values may "overestimate the population effect size" when samples are small (Johnson, 1993, p. 19), Cohen's $d$ values are reported here as calculated by the CMA program. Cohen's $d$ s between 0.20 and 0.50 indicate a small effect size, Cohen's $d$ s between 0.50 and 0.80 indicate a medium effect, and Cohen's $d$ s $>0.80$ indicate a large effect (Cohen, 1988). Of course, the effect size alone does not determine significance, and we determined the significance of effect sizes on the basis of the $p$ values of the resultant $Z$ scores.

\section{Post Hoc Comparisons}

After grouping the effect sizes by a particular moderator and finding significant heterogeneity among different levels of the same moderator, each level was compared with all others within the CMA program, indicated by $Q$, to determine whether the effect sizes between the groups were significantly different from one another. Post hoc $p$ values were adjusted for the number of comparisons conducted. For example, post hoc comparisons of the domain categories required 15 comparisons and consequently led to a set alpha level of .003 for levels to be considered significantly different from one another.

\section{Results}

The effect sizes comparing discovery conditions with other forms of instruction were analyzed in four separate meta-analyses, two at the level of studies and two at the level of comparisons. Table 2 displays the results overall for each of the meta-analyses and includes results for both fixed and random effects models. Effects sizes were coded so that a negative effect size indicates that participants in the compared instructional conditions evidenced greater learning than participants in discovery conditions, whereas a positive effect size indicates that participants in the discovery conditions evidenced greater learning than participants in the compared instructional conditions. Similarly, the effect sizes for the dependent measures of reaction times and mental effort/load were coded so that scores lower in number (i.e., faster reaction times, less mental effort), which reflect better performance, would consequently lead to positive effect sizes when the discovery group outperformed the comparison group.

\section{Moderators}

An advantage of quantitative meta-analytic techniques is the ability to examine potential moderators of relations with ample statistical power. In the present meta-analyses, the following potential moderators were investigated: publication rank, domain, age of participants, dependent variable, type of discovery condition, and type of compared instructional condition. Whenever heterogeneity of variance was indicated (Johnson, 1989), moderators were tested for each of the meta-analyses. Post hoc $p$ values were used to determine statistical significance. All moderators for both meta-analyses were examined using statistical comparisons as

Table 2

Summary of Effect Sizes

\begin{tabular}{|c|c|c|c|c|c|c|c|c|}
\hline Level of analysis & Cohen's $d$ & $95 \% \mathrm{CI}$ & $Z$ & $p$ value $(Z)$ & $N$ & $Q$ & $d f(Q)$ & $p$ value $(Q)$ \\
\hline \multicolumn{9}{|c|}{ Unassisted discovery } \\
\hline \multicolumn{9}{|l|}{ Studies } \\
\hline Fixed & -0.30 & {$[-.36,-.25]$} & -10.62 & .00 & 5,226 & 522.11 & 107 & .00 \\
\hline Random & -0.38 & {$[-.50,-.25]$} & -5.69 & .00 & 5,226 & & & \\
\hline \multicolumn{9}{|l|}{ Comparisons } \\
\hline Fixed & -0.30 & {$[-.32,-.27]$} & -23.08 & .00 & 25,986 & $3,490.42$ & 579 & .00 \\
\hline Random & -0.38 & {$[-.44,-.31]$} & -11.40 & .00 & 25,986 & & & \\
\hline \multicolumn{9}{|c|}{ Enhanced discovery } \\
\hline \multicolumn{9}{|l|}{ Studies } \\
\hline Fixed & 0.26 & {$[.20, .32]$} & 8.39 & .00 & 4,243 & 260.14 & 55 & .00 \\
\hline Random & 0.30 & {$[.15, .44]$} & 4.10 & .00 & 4,243 & & & \\
\hline \multicolumn{9}{|l|}{ Comparisons } \\
\hline Fixed & 0.24 & {$[.21, .26]$} & 18.61 & .00 & 25,925 & $2,037.19$ & 359 & .00 \\
\hline Random & 0.30 & {$[.23, .36]$} & 9.12 & .00 & 25,925 & & & \\
\hline
\end{tabular}


the unit of analysis, assuming independence, except for publication rank, which was examined at the level of studies.

\section{Unassisted Discovery}

Overall effects. A total of 580 comparisons from 108 studies compared unassisted discovery learning with more explicit teaching methods. Table 3 lists each sample. With the random effects analysis, the 108 studies had a mean effect size of $d=-0.38(95 \%$ CI $[-.50,-.25])$, indicating that explicit teaching was more beneficial to learning than unassisted discovery. This constitutes a small but meaningful effect size $(p<.001)$. The effects are highly heterogeneous across the studies, $Q(107)=522.11, p<.001$. Such heterogeneity is to be expected given the diversity of research methods, participant samples, and learning tasks. To address issues of publication bias, we calculated fail-safe $N$ s both at the level of comparisons and at the level of studies with alphas set to .05, two-tailed. At the level of comparisons, 3,588 unpublished studies would be needed to alter the results so that the effect would no longer be statistically significant. At the level of studies, 3,551 unpublished studies would be needed to reduce the effect to nonsignificance.

Moderators. First, using studies as the unit of analysis, the type of publication moderated the findings, $Q(3)=10.86, p<.05$. Articles in first-tier journals $(d=-0.67)$ evidenced larger effect sizes in favor of explicit instruction than did articles in second-tier publications $(d=-0.24)$. Post hoc comparisons revealed that these mean effect sizes were significantly different from one another, $Q(1)=10.20, p<.008$. Effect sizes from book chapters $(d=$ $-0.12)$ and unpublished works $(d=-0.01)$ did not reach significance.

The domain was also found to moderate effect sizes, $Q(5)=$ $91.75, p<.001$. In the domains of math $(d=-0.16)$, science $(d=$ $-0.39)$, problem solving $(d=-0.48)$, and verbal and social skills $(d=-0.95)$, participants evidenced less learning in the unassisteddiscovery conditions than in the explicit conditions. Post hoc comparisons indicated that the mean effect size favoring explicit conditions within the verbal/social skills domain was significantly greater than within the domains of math, $Q(1)=50.03, p<.001$; computer skills, $Q(1)=58.17, p<.001$; science, $Q(1)=22.65$, $p<.001$; problem solving, $Q(1)=18.35, p<.001$; and physical/ motor skills, $Q(1)=14.87, p<.001$. The mean effect size favoring explicit conditions within the domain of problem solving was also significantly greater than within the domains of math, $Q(1)=13.65, p<.001$, and computer skills, $Q(1)=28.29, p<$ .001. Lastly, the mean effect size favoring explicit conditions in the domain of science was significantly greater than within the domain of computer skills, $Q(1)=16.64, p<.001$.

The next moderator investigated was participant age, which also moderated the findings, $Q(2)=12.29, p<.01$. Effect sizes for all age groups showed significant advantages for more explicit instruction over unassisted discovery. Post hoc comparisons revealed that the mean effect size for adolescents $(d=-0.53)$ was significantly greater than the mean effect size for adults $(d=-0.26)$, $Q(1)=10.41, p=.001$. The type of dependent variable was also found to moderate the findings, $Q(5)=37.38, p<.001$. Measures of post-test scores $(d=-0.35)$, acquisition scores $(d=-0.95)$, and time to solution $(d=-0.21)$ favored participants in explicit conditions. Post hoc comparisons indicated that the measure of acquisition scores led to significantly greater effect sizes in favor of explicit conditions than did the measures of post-test scores, $Q(1)=31.41, p<.001$; time to solution, $Q(1)=23.84, p<.001$; and self-ratings, $Q(1)=15.89, p<.001$.

The type of unassisted-discovery condition moderated the findings, $Q(4)=10.02, p<.05$, but post hoc comparisons failed to reveal any reliable differences. Performances were better under explicit conditions than they were in conditions in which learners worked with a naïve peer $(d=-0.47)$, engaged in unassisted discovery $(d=-0.41)$, and engaged in invention tasks $(d=$ -0.34). Next, we investigated the explicit conditions to which unassisted-discovery conditions were compared. The type of explicit condition moderated the findings, $Q(5)=32.31, p<.001$. Participants in unassisted discovery fared worse than participants in comparison conditions of direct teaching $(d=-0.29)$, feedback ( $d=-0.46)$, worked examples $(d=-0.63)$, and explanations provided $(d=-0.28)$. Post hoc comparisons revealed that effect sizes for direct teaching and worked examples were significantly different from one another, $Q(1)=18.98, p<.001$, and indicated that participants learning with worked examples outperformed participants learning through unassisted discovery to a greater extent than did participants learning from direct teaching outperformed participants learning from unassisted discovery. Post hoc comparisons also revealed that feedback, $Q(1)=9.15, p<.003$, and worked examples, $Q(1)=13.70, p<.001$, benefitted learners more than having no exposure with pre- and post-tests only.

Overall, the findings indicate that explicit-instructional conditions lead to greater learning than do unassisted-discovery conditions. The lack of significant differences between the mean effect sizes of the unassisted-discovery conditions helps to illustrate that claim (see Tables 1-5 in the supplemental materials).

\section{Enhanced Discovery}

Overall effects. A total of 360 comparisons from 56 studies compared enhanced discovery learning (i.e., generation, elicited explanation, or guided discovery) with other types of instructional methods. Table 4 lists each sample. With the random effects analysis, the 56 studies had a mean effect size of $d=0.30(95 \%$ CI $[.15, .44])$, indicating that enhanced-discovery methods led to greater learning than did comparison methods of instruction. This constitutes a small but meaningful effect size $(p<.001)$. The effects are highly heterogeneous across the studies, $Q(55)=$ 260.14, $p<.001$. Again, such heterogeneity is to be expected given the diversity of research methods, participant samples, and learning tasks. To address issues of publication bias, we calculated fail-safe $\mathrm{Ns}$ both at the level of comparisons and at the level of studies with alphas set to .05 , two-tailed. At the level of comparisons, 4,138 unpublished studies would be needed to reduce the effects to nonsignificance. At the level of studies, 960 unpublished studies would be needed to reduce effects to nonsignificance.

Moderators. First, using studies as the unit of analysis, the type of publication moderated the findings, $Q(2)=18.66, p=$ .001. Articles in first-tier journals $(d=0.35)$ and second-tier journals $(d=0.40)$ generally favored enhanced-discovery conditions, whereas data sets from unpublished studies and dissertations did not $(d=-0.54)$. Post hoc comparisons revealed that although the effect sizes derived from first-tier and second-tier journal articles were not significantly different, $Q(1)=0.10, n s$, the mean 
Table 3

Samples Included in the Unassisted Discovery Meta-Analysis

\begin{tabular}{|c|c|c|c|c|c|c|c|}
\hline Author(s) & Year & $\begin{array}{c}\text { Discovery } \\
n\end{array}$ & $\begin{array}{c}\text { Comparison } \\
n\end{array}$ & $\begin{array}{c}\text { Cohen's } \\
d\end{array}$ & Domain & Age group & Journal rank \\
\hline Alibali & 1999 & 26 & 29.25 & -0.89 & Math/numbers & Children & Journal $\geq 1.5$ \\
\hline Anastasiow et al. & 1970 & 6 & 6 & -0.06 & Math/numbers & Children & Journal $<1.5$ \\
\hline Bannert & 2000 & 37 & 35 & 0.74 & Computer skills & Adults & Journal $<1.5$ \\
\hline Belcastro & 1966 & 189 & 189 & -0.26 & Math/numbers & Adolescents & Journal $<1.5$ \\
\hline Bobis et al. (Experiment 1) & 1994 & 15 & 15 & 1.07 & Math/numbers & Children & Journal $<1.5$ \\
\hline Bobis et al. (Experiment 2) & 1994 & 10 & 10 & 1.11 & Math/numbers & Children & Journal $<1.5$ \\
\hline Bransford \& Johnson (Experiment 1) & 1972 & 10 & 10 & -0.63 & Verbal/social skills & Adolescents & Journal $\geq 1.5$ \\
\hline Bransford \& Johnson (Experiment 2) & 1972 & 17 & 17.5 & -0.60 & Verbal/social skills & Adults & Journal $\geq 1.5$ \\
\hline Bransford \& Johnson (Experiment 4) & 1972 & 9 & 11 & -0.50 & Verbal/social skills & Adolescents & Journal $\geq 1.5$ \\
\hline Brant et al. & 1991 & 33 & 35 & 0.55 & Science & Adults & Journal $<1.5$ \\
\hline Brown et al. (Experiment 3) & 1989 & 21 & 16 & -0.17 & Problem solving & Children & Journal $<1.5$ \\
\hline Butler et al. & 2006 & 34 & 28 & -0.01 & Math/numbers & Children & Unpublished/dissertation \\
\hline Cantor et al. & 1982 & 24 & 24 & -0.46 & Math/numbers & Children & Journal $<1.5$ \\
\hline Carroll (Experiment 1) & 1994 & 16.8 & 16.8 & -0.89 & Math/numbers & Adolescents & Journal $\geq 1.5$ \\
\hline Carroll (Experiment 2) & 1994 & 12 & 12 & -2.05 & Math/numbers & Adolescents & Journal $\geq 1.5$ \\
\hline Charney et al. & 1990 & 20 & 45 & -0.33 & Computer skills & Adults & Journal $<1.5$ \\
\hline Craig & 1965 & 30 & 30 & -0.11 & Math/numbers & Adults & Journal $<1.5$ \\
\hline Danner \& Day & 1977 & 20 & 20 & -0.86 & Science & Adolescents & Journal $\geq 1.5$ \\
\hline Destrebecqz (Experiment 1) & 2004 & 20 & 20 & -0.56 & Problem solving & Adults & Journal $<1.5$ \\
\hline Destrebecqz (Experiment 2) & 2004 & 12 & 12 & -2.36 & Problem solving & Adults & Journal $<1.5$ \\
\hline Elias \& Allen & 1991 & 37.86 & 34.43 & -0.01 & Problem solving & Children & Journal $<1.5$ \\
\hline Elshout \& Veenman (Experiment 1) & 1992 & 4.5 & 4.25 & -0.19 & Science & Adults & Journal $<1.5$ \\
\hline Elshout \& Veenman (Experiment 2) & 1992 & 4.4 & 5 & -0.24 & Science & Adults & Journal $<1.5$ \\
\hline Fender \& Crowley (Experiment 2) & 2007 & 12 & 12 & -1.04 & Science & Children & Journal $<1.5$ \\
\hline Guthrie & 1967 & 18 & 18 & -0.64 & Problem solving & Adults & Journal $\geq 1.5$ \\
\hline Hendrickson \& Schroeder & 1941 & 30 & 30 & -0.32 & Physical/motor skills & Adolescents & Journal $\geq 1.5$ \\
\hline Hendrix & 1947 & 13 & 13.5 & 0.51 & Math/numbers & Adults & Journal $<1.5$ \\
\hline Hodges \& Lee & 1999 & 8 & 8.5 & 0.39 & Physical/motor skills & Adults & Journal $<1.5$ \\
\hline Howe et al. (Experiment 2) & 2005 & 36 & 36 & 0.43 & Science & Children & Journal $<1.5$ \\
\hline Howe et al. (Experiment 3) & 2005 & 36 & 36 & 0.29 & Science & Children & Journal $<1.5$ \\
\hline Jackson et al. & 1992 & 36 & 24 & -0.23 & Math/numbers & Children & Journal $<1.5$ \\
\hline Jiménez et al. & 1996 & 6 & 6 & 0.00 & Verbal/social skills & Adults & Journal $\geq 1.5$ \\
\hline Kalyuga et al. (Experiment 1) & 2001 & 9 & 8 & -0.78 & Math/numbers & Adults & Journal $<1.5$ \\
\hline Kalyuga et al. (Experiment 2) & 2001 & 9 & 8 & -0.28 & Math/numbers & Adults & Journal $<1.5$ \\
\hline Kalyuga et al. (Experiment 1) & 2001 & 12 & 12 & -0.53 & Computer skills & Adults & Journal $\geq 1.5$ \\
\hline Kalyuga et al. (Experiment 2) & 2001 & 12 & 12 & 0.70 & Computer skills & Adults & Journal $\geq 1.5$ \\
\hline Kamii \& Dominick & 1997 & 16.29 & 16.71 & 0.21 & Math/numbers & Children & Journal $<1.5$ \\
\hline Kelemen & 2003 & 12 & 11 & -0.82 & Science & Children & Journal $\geq 1.5$ \\
\hline Kersh & 1958 & 16 & 16 & -0.18 & Math/numbers & Adults & Journal $\geq 1.5$ \\
\hline Kersh & 1962 & 10 & 10 & 0.50 & Math/numbers & Adolescents & Journal $\geq 1.5$ \\
\hline King & 1991 & 8 & 7.5 & -0.58 & Problem solving & Children & Journal $\geq 1.5$ \\
\hline Kittell & 1957 & 45 & 43.5 & -0.78 & Verbal/social skills & Children & Journal $\geq 1.5$ \\
\hline Klahr \& Nigam & 2004 & 52 & 52 & -1.14 & Science & Children & Journal $\geq 1.5$ \\
\hline Kuhn \& Dean & 2005 & 12 & 12 & -1.18 & Science & Children & Journal $\geq 1.5$ \\
\hline Lawson \& Wollman & 1976 & 16 & 16 & -0.82 & Science & Adolescents & Journal $<1.5$ \\
\hline Lazonder \& van der Meij & 1993 & 30 & 34 & 0.67 & Computer skills & Adults & Journal $<1.5$ \\
\hline Lazonder \& van der Meij & 1994 & 21 & 21 & 0.05 & Computer skills & Adults & Journal $<1.5$ \\
\hline Lazonder \& van der Meij & 1995 & 25 & 25 & -0.44 & Computer skills & Adults & Journal $<1.5$ \\
\hline Lee \& Thompson & 1997 & 66 & 64 & -0.92 & Computer skills & Adults & Journal $<1.5$ \\
\hline Leutner (Experiment 1) & 1993 & 16 & 16 & -0.09 & Problem solving & Adolescents & Journal $<1.5$ \\
\hline Leutner (Experiment 2) & 1993 & 19 & 19 & -0.36 & Problem solving & Adults & Journal $<1.5$ \\
\hline Leutner (Experiment 3) & 1993 & 20 & 20 & -0.38 & Problem solving & Adolescents & Journal $<1.5$ \\
\hline McDaniel \& Pressley (Experiment 1) & 1984 & 16.6 & 17.6 & -1.21 & Verbal/social skills & Adults & Journal $\geq 1.5$ \\
\hline McDaniel \& Pressley (Experiment 2) & 1984 & 21 & 21 & -1.06 & Verbal/social skills & Adults & Journal $\geq 1.5$ \\
\hline McDaniel \& Schlager (Experiment 1) & 1990 & 31 & 29.5 & 0.00 & Problem solving & Adults & Journal $<1.5$ \\
\hline McDaniel \& Schlager (Experiment 2) & 1990 & 60 & 60 & 0.42 & Problem solving & Adults & Journal $<1.5$ \\
\hline Messer et al. (Experiment 1) & 1993 & 14 & 13 & 0.32 & Science & Children & Journal $<1.5$ \\
\hline Messer et al. (Experiment 2) & 1993 & 18 & 20 & -1.14 & Science & Children & Journal $<1.5$ \\
\hline Messer, Mohamedali, \& Fletcher & 1996 & 21 & 20 & 0.34 & Problem solving & Children & Journal $<1.5$ \\
\hline Messer, Norgate, et al. (Experiment 1) & 1996 & 11.75 & 10.5 & -0.89 & Science & Children & Journal $<1.5$ \\
\hline Messer, Norgate, et al. (Experiment 2) & 1996 & 16 & 15 & 0.43 & Science & Children & Journal $<1.5$ \\
\hline Morton et al. (Experiment 2) & 2003 & 15.29 & 16.14 & -2.19 & Verbal/social skills & Children & Journal $\geq 1.5$ \\
\hline Mwangi \& Sweller (Experiment 1) & 1998 & 9 & 9 & -0.46 & Math/numbers & Children & Journal $<1.5$ \\
\hline
\end{tabular}


Table 3 (continued)

\begin{tabular}{|c|c|c|c|c|c|c|c|}
\hline Author(s) & Year & $\begin{array}{c}\text { Discovery } \\
n\end{array}$ & $\begin{array}{c}\text { Comparison } \\
n\end{array}$ & $\begin{array}{c}\text { Cohen's } \\
d\end{array}$ & Domain & Age group & Journal rank \\
\hline Nadolski et al. & 2005 & 11 & 12 & 0.09 & Problemsolving & Adults & Journal $<1.5$ \\
\hline O’Brien \& Shapiro & 1977 & 15 & 15 & -0.15 & Math/numbers & Adults & Journal $<1.5$ \\
\hline Paas & 1992 & 13 & 15 & -2.25 & Math/numbers & Adolescents & Journal $\geq 1.5$ \\
\hline Paas \& Van Merriënboer & 1994 & 30 & 30 & -0.77 & Problemsolving & Adults & Journal $\geq 1.5$ \\
\hline Pany \& Jenkins & 1978 & 6 & 6 & -1.93 & Verbal/social skills & Children & Journal $<1.5$ \\
\hline Peters & 1970 & 30 & 30 & 0.25 & Math/numbers & Children & Journal $<1.5$ \\
\hline Pillay (Experiment 1) & 1994 & 10 & 20 & -1.09 & Problemsolving & Adolescents & Journal $<1.5$ \\
\hline Pillay (Experiment 2) & 1994 & 10 & 20 & -0.78 & Problemsolving & Adolescents & Journal $<1.5$ \\
\hline Pine et al. & 1999 & 14 & 14 & -0.74 & Science & Children & Journal $<1.5$ \\
\hline Quilici \& Mayer (Experiment 1) & 1996 & 27 & 54 & 0.92 & Math/numbers & Adults & Journal $\geq 1.5$ \\
\hline Quilici \& Mayer (Experiment 2) & 1996 & 18 & 18 & -1.69 & Math/numbers & Adults & Journal $\geq 1.5$ \\
\hline Radziszewska \& Rogoff & 1991 & 20 & 20 & -1.25 & Problemsolving & Children & Journal $\geq 1.5$ \\
\hline Rappolt-Schlichtmann et al. & 2007 & 27 & 37 & -0.61 & Science & Children & Journal $<1.5$ \\
\hline Reinking \& Rickman & 1990 & 45 & 15 & -1.09 & Verbal/social skills & Children & Journal $<1.5$ \\
\hline Rieber \& Parmley & 1995 & 25 & 27.5 & -0.65 & Science & Adults & Journal $<1.5$ \\
\hline Rittle-Johnson & 2006 & 21 & 21.5 & -0.23 & Math/numbers & Children & Journal $\geq 1.5$ \\
\hline Salmon et al. & 2007 & 16 & 16 & -1.66 & Verbal/social skills & Children & Journal $<1.5$ \\
\hline Scandura (Experiment 2) & 1964 & 23 & 23 & 0.00 & Math/numbers & Children & Journal $<1.5$ \\
\hline Shore \& Durso & 1990 & 60 & 60 & -0.14 & Verbal/social skills & Adults & Journal $\geq 1.5$ \\
\hline Shute et al. & 1989 & 10 & 10 & 0.42 & Math/numbers & Adults & Book chapter \\
\hline Siegel \& Corsini & 1969 & 12 & 12 & -0.90 & Problemsolving & Children & Journal $\geq 1.5$ \\
\hline Singer \& Gaines & 1975 & 19 & 18 & -0.27 & Physical/motor skills & Adults & Journal $<1.5$ \\
\hline Stark et al. & 1998 & 15 & 15 & -0.54 & Math/numbers & Adults & Journal $<1.5$ \\
\hline Strand-Cary \& Klahr & 2008 & 29 & 32 & -0.85 & Science & Children & Journal $<1.5$ \\
\hline Sutherland et al. & 2003 & 12 & 11.5 & -0.10 & Verbal/social skills & Children & Journal $<1.5$ \\
\hline Swaak et al. & 2004 & 67 & 55 & -0.56 & Science & Adolescents & Journal $<1.5$ \\
\hline Swaak et al. & 1998 & 21 & 21 & -0.44 & Science & Adults & Journal $<1.5$ \\
\hline Sweller et al. (Experiment 1) & 1990 & 16 & 16 & 0.20 & Math/numbers & Adolescents & Journal $\geq 1.5$ \\
\hline Sweller et al. (Experiment 3) & 1990 & 12 & 12 & -1.78 & Math/numbers & Adolescents & Journal $\geq 1.5$ \\
\hline Tarmizi \& Sweller (Experiment 3) & 1988 & 10 & 10 & 0.20 & Math/numbers & Adolescents & Journal $\geq 1.5$ \\
\hline Tarmizi \& Sweller (Experiment 4) & 1988 & 10 & 10 & 0.28 & Math/numbers & Adolescents & Journal $\geq 1.5$ \\
\hline Tarmizi \& Sweller (Experiment 5) & 1988 & 10 & 10 & -0.71 & Math/numbers & Adolescents & Journal $\geq 1.5$ \\
\hline Trafton \& Reiser & 1993 & 20 & 20 & 0.39 & Computer skills & Adults & Journal $<1.5$ \\
\hline Tunteler \& Resing & 2002 & 18 & 18 & -2.19 & Problem solving & Children & Journal $<1.5$ \\
\hline van der Meij \& Lazonder & 1993 & 13 & 12 & 1.03 & Computer skills & Adults & Journal $<1.5$ \\
\hline van hout Wolters & 1990 & 24 & 24 & -0.54 & Science & Adolescents & Book chapter \\
\hline Veenman et al. & 1994 & 15 & 14 & -0.49 & Science & Adults & Journal $<1.5$ \\
\hline Ward \& Sweller (Experiment 1) & 1990 & 21 & 21 & -1.07 & Science & Adolescents & Journal $<1.5$ \\
\hline Ward \& Sweller (Experiment 2) & 1990 & 16 & 16 & -1.52 & Science & Adolescents & Journal $<1.5$ \\
\hline Ward \& Sweller (Experiment 3) & 1990 & 17 & 17 & 0.25 & Science & Adolescents & Journal $<1.5$ \\
\hline Ward \& Sweller (Experiment 4) & 1990 & 15 & 15 & -0.42 & Science & Adolescents & Journal $<1.5$ \\
\hline Ward \& Sweller (Experiment 5) & 1990 & 15.5 & 15.5 & -0.47 & Science & Adolescents & Journal $<1.5$ \\
\hline Wittrock & 1963 & 67 & 75 & -0.84 & Verbal/social skills & Adults & Journal $\geq 1.5$ \\
\hline Worthen & 1968 & 216 & 216 & 0.08 & Math/numbers & Children & Journal $<1.5$ \\
\hline Zacharia \& Anderson & 2003 & 13 & 13 & 4.62 & Science & Adults & Journal $<1.5$ \\
\hline
\end{tabular}

effect size from unpublished works and dissertations differed from both the mean effect size from first-tier journals, $Q(1)=9.65, p<$ .003 , and the mean effect size from second-tier journals, $Q(1)=$ $21.59, p<.001$.

Domain was also found to moderate the findings, $Q(5)=65.53$, $p<.001$. In the domains of math $(d=0.29)$, computer skills $(d=$ $0.64)$, science $(d=0.11)$, physical/motor $(d=1.05)$, and verbal and social skills $(d=0.58)$, participants evidenced more learning in the enhanced-discovery conditions than in the comparison conditions. Post hoc comparisons indicated that the mean effect size in the physical/motor domain was significantly greater than the effect sizes in the domains of math, $Q(1)=34.59, p<.001$; science, $Q(1)=41.67, p<.001$; and problem solving, $Q(1)=15.73, p<$ .001. Also, the mean effect size for the domain of computer skills was significantly greater than the effect sizes in the domains of math, $Q(1)=12.14, p<.001$, and science, $Q(1)=18.65, p<$ .001 .

The next moderator, participant age, also influenced the findings, $Q(2)=10.68, p<.01$. Post hoc comparisons revealed that the mean effect size for adults was significantly greater than the effect size for children, $Q(1)=7.64, p<.01$. Although superficially there was a greater difference between the mean effect sizes of adults and adolescents, that difference was not found to be significant because of the larger variance within the adolescents (95\% CI $[.04, .33])$. Next, the type of dependent variable was found to moderate the findings, $Q(4)=64.60, p<.001$. Measures of post-test scores $(d=0.28)$, acquisition scores $(d=0.54)$, and self-ratings $(d=1.25)$ favored participants in enhanced-discovery conditions over participants in comparison conditions, whereas measures of reaction times $(d=-0.72)$ favored participants in 
Table 4

Studies Included in the Enhanced Discovery Meta-Analysis

\begin{tabular}{|c|c|c|c|c|c|c|c|}
\hline Author(s) & Year & $\begin{array}{c}\text { Discovery } \\
n\end{array}$ & $\begin{array}{c}\text { Comparison } \\
n\end{array}$ & $\begin{array}{c}\text { Cohen's } \\
d\end{array}$ & Domain & Age group & Journal rank \\
\hline Amsterlaw \& Wellman & 2006 & 12 & 12 & 1.11 & Verbal/social skills & Children & Journal $<1.5$ \\
\hline Anastasiow et al. & 1970 & 6 & 6 & -0.08 & Math/numbers & Children & Journal $<1.5$ \\
\hline Andrews & 1984 & 25 & 28 & 1.27 & Science & Adults & Journal $<1.5$ \\
\hline Bielaczyc et al. & 1995 & 11 & 13 & 0.95 & Computer skills & Adults & Journal $<1.5$ \\
\hline Bluhm & 1979 & 20 & 17 & 1.44 & Science & Adults & Journal $<1.5$ \\
\hline Bowyer \& Linn & 1978 & 312 & 219 & 0.20 & Science & Children & Journal $<1.5$ \\
\hline Butler et al. & 2006 & 32 & 31 & -0.02 & Math/numbers & Children & Unpublished/dissertation \\
\hline Chen \& Klahr & 1999 & 30 & 30 & -0.07 & Science & Children & Journal $\geq 1.5$ \\
\hline Chi et al. & 1994 & 14 & 10 & 0.94 & Science & Adolescents & Journal $\geq 1.5$ \\
\hline Coleman et al. & 1997 & 14 & 14 & 0.61 & Science & Adults & Journal $<1.5$ \\
\hline Crowley \& Siegler & 1999 & 57 & 57 & -0.25 & Problem solving & Children & Journal $\geq 1.5$ \\
\hline Debowski et al. & 2001 & 24 & 24 & 1.07 & Computer skills & Adults & Journal $\geq 1.5$ \\
\hline Denson & 1986 & 45 & 34 & 0.10 & Science & Adults & Unpublished/dissertation \\
\hline Foos et al. (Experiment 1$)$ & 1994 & 78 & 90 & 0.53 & Science & Adults & Journal $\geq 1.5$ \\
\hline Foos et al. (Experiment 2) & 1994 & 25 & 25 & 0.71 & Science & Adults & Journal $\geq 1.5$ \\
\hline Gagné \& Brown & 1961 & 11 & 11 & 1.41 & Math/numbers & Adolescents & Journal $\geq 1.5$ \\
\hline Ginns et al. (Experiment 1) & 2003 & 10 & 10 & -0.67 & Computer skills & Adults & Journal < 1.5 \\
\hline Ginns et al. (Experiment 2) & 2003 & 13 & 13 & 0.67 & Math/numbers & Adolescents & Journal $<1.5$ \\
\hline Grandgenett \& Thompson & 1991 & 72 & 71 & 0.05 & Computer skills & Adults & Journal < 1.5 \\
\hline Greenockle \& Lee & 1991 & 20 & 20 & 0.48 & Physical/motor skills & Adults & Journal $<1.5$ \\
\hline Hiebert \& Wearne & 1993 & 24 & 21.25 & 0.70 & Math/numbers & Children & Journal $<1.5$ \\
\hline Hirsch & 1977 & 61 & 76 & 0.56 & Math/numbers & Adolescents & Journal $<1.5$ \\
\hline Howe et al. (Experiment 1$)$ & 2005 & 31 & 30 & 0.15 & Science & Children & Journal $<1.5$ \\
\hline Howe et al. (Experiment 2) & 2005 & 35 & 36 & 0.15 & Science & Children & Journal $<1.5$ \\
\hline Howe et al. (Experiment 3) & 2005 & 35.5 & 36 & 0.34 & Science & Children & Journal < 1.5 \\
\hline Jackson et al. & 1992 & 12 & 24 & 0.01 & Math/numbers & Children & Journal $<1.5$ \\
\hline Kasten \& Liben & 2007 & 34 & 99 & 0.42 & Problem solving & Children & Journal $\geq 1.5$ \\
\hline Kersh & 1958 & 16 & 16 & 0.12 & Math/numbers & Adults & Journal $\geq 1.5$ \\
\hline Kersh & 1962 & 10 & 10 & -0.10 & Math/numbers & Adolescents & Journal $\geq 1.5$ \\
\hline Kuhn et al. & 2000 & 21 & 21 & 0.29 & Science & Adolescents & Journal $<1.5$ \\
\hline Lamborn et al. & 1994 & 113 & 113 & 1.06 & Verbal/social skills & Adolescents & Journal $\geq 1.5$ \\
\hline Murphy \& Messer & 2000 & 41 & 40.5 & 0.46 & Science & Children & Journal $<1.5$ \\
\hline Mwangi \& Sweller (Experiment 3) & 1998 & 12 & 12 & -0.04 & Math/numbers & Children & Journal $<1.5$ \\
\hline Öhrn et al. & 1997 & 11 & 12 & 0.99 & Science & Adults & Journal $\geq 1.5$ \\
\hline Olander \& Robertson & 1973 & 190 & 184 & -0.02 & Math/numbers & Children & Journal $<1.5$ \\
\hline Peters & 1970 & 30 & 30 & -0.09 & Math/numbers & Children & Journal $<1.5$ \\
\hline Pillow et al. & 2002 & 15 & 15 & 0.44 & Verbal/social skills & Children & Journal $<1.5$ \\
\hline Pine \& Messer & 2000 & 40 & 44 & 0.55 & Science & Children & Journal $<1.5$ \\
\hline Pine et al. & 1999 & 14 & 14 & -0.35 & Science & Children & Journal $<1.5$ \\
\hline Ray & 1961 & 45 & 45 & 0.44 & Math/numbers & Adolescents & Journal $<1.5$ \\
\hline Reid et al. & 2003 & 20 & 18 & 0.16 & Science & Adolescents & Journal $<1.5$ \\
\hline Rittle-Johnson & 2006 & 22 & 21 & 0.19 & Math/numbers & Children & Journal $\geq 1.5$ \\
\hline Rittle-Johnson et al. & 2008 & 36 & 18 & 0.81 & Problem solving & Children & Journal $<1.5$ \\
\hline Scandura (Experiment 1) & 1964 & 23 & 23 & 0.00 & Math/numbers & Children & Journal $<1.5$ \\
\hline Singer \& Pease & 1978 & 16 & 16 & 2.62 & Physical/motor skills & Adults & Journal $<1.5$ \\
\hline Stark et al. & 2002 & 27 & 27 & 0.94 & Math/numbers & Adults & Journal $<1.5$ \\
\hline Stull \& Mayer (Experiment 1) & 2006 & 51 & 52.5 & -0.60 & Science & Adults & Unpublished/dissertation \\
\hline Stull \& Mayer (Experiment 2) & 2006 & 38 & 39 & -1.14 & Science & Adults & Unpublished/dissertation \\
\hline Stull \& Mayer (Experiment 3) & 2006 & 33 & 32.5 & -1.10 & science & Adults & Unpublished/dissertation \\
\hline Tarmizi \& Sweller (Experiment 2) & 1988 & 12 & 12 & -0.08 & Math/numbers & Adolescents & Journal $\geq 1.5$ \\
\hline Tenenbaum et al. & 2008 & 32 & 30.5 & 0.20 & Verbal/social skills & Children & Journal $<1.5$ \\
\hline Tuovinen \& Sweller & 1999 & 16 & 16 & -0.67 & Computer skills & Adults & Journal $\geq 1.5$ \\
\hline Vichitvejpaisal et al. & 2001 & 40 & 40 & -0.28 & Science & Adults & Journal $\geq 1.5$ \\
\hline Zhang et al. (Experiment 1) & 2004 & 13 & 13.67 & -0.16 & Computer skills & Adolescents & Journal $<1.5$ \\
\hline Zhang et al. (Experiment 2) & 2004 & 14 & 16 & 0.36 & Computer skills & Adolescents & Journal $<1.5$ \\
\hline Zimmerman \& Sassenrath & 1978 & 119.67 & 119.67 & 0.51 & Math/numbers & Children & Journal $<1.5$ \\
\hline
\end{tabular}

comparison conditions over participants in enhanced-discovery conditions. Post hoc comparisons indicated that the measure of post-test scores led to significantly greater effect sizes in favor of participants in enhanced-discovery conditions than did the measure of self-ratings, $Q(1)=29.68, p<.001$. Comparisons also indicated that the mean effect size derived from reaction time measures was significantly different (i.e., significantly opposite in effect size direction) from both the mean effect size derived from acquisition scores, $Q(1)=10.19, p=.001$, and the mean effect size derived from post-tests, $Q(1)=31.61, p<.001$. Lastly, the 
mean effect size for self-ratings that favored enhanced discovery was found to be significantly different (i.e., opposite) to the mean effect size for mental effort/load, which showed trends favoring other forms of instruction.

The type of enhanced-discovery condition used also moderated the findings, $Q(2)=65.00, p<.001$. Elicited explanation $(d=$ $0.36)$ and guided discovery $(d=0.50)$ favored enhanced discovery, whereas generation $(d=-0.15)$ favored other instructional methods. Post hoc comparisons indicated that indeed, generation conditions were significantly different in their effect sizes when compared with both elicited explanation, $Q(1)=33.20, p<.001$, and guided discovery, $Q(1)=57.43, p<.001$, but the effect sizes for elicited explanation and guided discovery did not differ from one another. Next, we investigated the instructional conditions to which enhanced-discovery conditions were compared but the type of comparison condition failed to moderate the findings, $Q(4)=$ $9.12, p=.06$. With the exception of worked examples $(d=0.06$, $n s$ ), all other comparisons conditions indicated significantly superior performances in the enhanced-discovery conditions.

Overall, results seem to favor enhanced-discovery methods over other forms of instruction. However, the dependent measure and the type of enhanced discovery employed affected the outcome assessments (see Tables 6-10 in the supplemental materials).

\section{Discussion}

In the first meta-analysis, our intention was to investigate under which conditions unassisted discovery learning might lead to better learning outcomes than explicit-instructional tasks. However, more explicit-instructional tasks were found to be superior to unassisted-discovery tasks. Moreover the type of publication, the domain of study, the age of participants, the dependent measure, the type of unassisted-discovery task, and the comparison condition all moderated outcomes. Post hoc comparisons revealed that on average, publications in first-tier journals showed greater benefits for explicit-instructional tasks than did publications in second-tier journals. Among the variety of different domains in which more explicit instruction was found to benefit learners, verbal and social learning tasks seemed to favor explicit instruction most, followed by problem solving and science. Adolescents were found to benefit significantly more from explicit instruction than did adults. Analysis of dependent measures indicated that learners' acquisition scores showed a greater detriment under discovery conditions than did post-test scores, time to solution, and self-ratings. Although the type of unassisted-discovery task moderated trends favoring explicit instruction, unassisted tasks, tasks requiring invention, and tasks involving collaboration with a naïve peer were all found to be equally detrimental to learning. Analyses of the types of explicit instruction in the comparison conditions indicated that worked examples benefited learners more than direct teaching and also indicated that feedback and providing explanations are useful aids to learning. The finding that worked examples evidenced greater learning than did unassisted discovery is expected given the worked-example effect (Sweller et al., 2007). However, the finding that worked examples benefitted learners to a greater extent than did direct teaching was unexpected.

In the second meta-analysis, we investigated under which conditions enhanced forms of discovery-learning tasks might be beneficial. This meta-analysis showed better learning for enhanced- discovery instructional methods, with the type of publication, the domain, the age of participants, the dependent measure, and the type of enhanced-discovery task moderating the findings. Unpublished studies and dissertations were found to show disadvantages for enhanced-discovery conditions, whereas first- and second-tier journal articles favored enhanced discovery. Of the different task domains, physical/motor skills, computer skills, and verbal and social skills benefited most from enhanced discovery. Because of concerns that the domain category of physical/motor skills might be dominating the overall analysis of enhanced discovery, those 24 comparisons were removed, and analyses were run again. The removal of physical/motor skills from the overall analyses under the random effects model only reduced the mean effect size slightly (i.e., from $d=0.30$ to $d=0.25$ ). Consequently, we retained the category of physical/motor skills within our analyses.

Analyses revealed that adult participants benefit more from enhanced discovery than children. Of the three types of enhanced discovery, the generation method of enhanced discovery failed to produce learning benefits over other instructional methods, which was unexpected given the typical benefits reported as the generation effect (Bertsch, Pesta, Wiscott, \& McDaniel, 2007; Slamecka $\&$ Graf, 1978). It should be noted that the advantage of other forms of instruction over generation also led to the finding that unpublished studies and dissertations showed an advantage for other forms of instruction over enhanced discovery. This was due to the fact that four out of the five studies sampled from unpublished works or dissertations employed generation conditions. Although the meta-analysis indicated that the type of comparison condition did not moderate the results, note that enhanced discovery was generally better than both direct teaching and explanations provided. Thus, the construction of explanations or participation in guided discovery is better for learners than being provided with an explanation or explicitly taught how to succeed on a task, in support of constructivist claims. Analysis of the dependent measure indicated that although learners' post-test and acquisition scores benefited from enhanced-discovery tasks, reaction times did not. This suggests that learners may take more time to find problem solutions or to perform target responses when engaged in enhanced-discovery tasks.

In regard to the large mean effect size for the category of comparison conditions labeled other, it should be noted that this category included only two comparisons; these two comparisons were included to ensure a complete inclusion of comparison conditions, despite the fact that they did not fit into the other categories. The participants in the first other comparison condition were asked the same questions that were asked of the elicited explanations group, but the elicited explanations condition required participants to provide a specific target answer before proceeding to the next question, and the comparison condition did not. The participants in the second other comparison condition were asked to discuss how/why things balance on a beam within a group without input from the experimenter and were compared with participants who were asked to explain to the experimenter who guided the learner with subsequent questions toward the target explanation.

The moderating effect of age across the two meta-analyses did not follow the expected pattern of results. First, the adolescent age group was shown to benefit least from unassisted-discovery conditions, as opposed to the children, as had been predicted. 
Although enhanced-discovery conditions led to better learning outcomes for all age groups, adults seemed to benefit from enhanced-discovery tasks more so than children. Interestingly, the adolescents tended to benefit least and the adults tended to benefit most from both unassisted-discovery tasks and enhanceddiscovery tasks. One might speculate that the negative trend among adolescents could reflect a general lack of motivation or lack of domain-relevant knowledge (Mayer, 2009). However, if the trend was the result of a lack of domain-relevant knowledge, one might expect to see even larger deficits in children. With regards to the adults, perhaps their greater domain-relevant knowledge helped them to succeed on unassisted-discovery tasks to a greater extent than the adolescents. It is also possible that the tasks used in the enhanced-discovery studies were more appropriate for adult learners (e.g., having participants explain the strategies they were using to solve problems) than for young learners. Organizing guidance to facilitate discovery requires sensitivity to the learner's zone of proximal development (Pea, 2004; Vygotsky, 1962) if it is to be maximally useful.

\section{Implications for Teaching}

The results of the first meta-analysis indicate that unassisted discovery generally does not benefit learning. Although direct teaching is better than unassisted discovery, providing learners with worked examples or timely feedback is preferable. Whereas providing well-timed, individualized feedback to all learners might be impossible (e.g., in a classroom setting), providing such feedback on homework assignments seems possible and worthwhile. Students might also benefit from having worked examples provided on those homework assignments, when the content allows for it. Furthermore, the second meta-analysis suggests that teaching practices should employ scaffolded tasks that have support in place as learners attempt to reach some objective, and/or activities that require learners to explain their own ideas. The benefits of feedback, worked examples, scaffolding, and elicited explanation can be understood to be part of a more general need for learners to be redirected, to some extent, when they are mis-constructing. Feedback, scaffolding, and elicited explanations do so in more obvious ways through an interaction with the instructor, but worked examples help lead learners through problem sets in their entireties and perhaps help to promote accurate constructions as a result. Although our suggestions are conservative as to how to apply the current findings, we suspect and hope that these analyses will be influential in subsequent designs, both instructional and empirical.

\section{Theoretical Implications}

Perhaps the inferior outcomes of unassisted-discovery tasks should not be surprising; Hake (2004) referred to such methods as extreme modes of discovery and pointed out that methods with almost no teacher guidance will, of course, be inferior to more guided methods. It does not seem that many researchers on either side of the argument would disagree with such a claim (Tobias \& Duffy, 2009). Nonetheless, it seems that many of Mayer's (2004) concerns are justified. Unassisted-discovery tasks appear inferior to more instructionally guided tasks, whether explicit instruction or enhanced discovery. Mayer's concern that unassisted-discovery tasks do not lead learners to construct accurate understandings of the problem set illustrates the potential disconnect between activity and constructivist learning. As Mayer has pointed out, it has been the accepted practice to consider hands-on activities as equivalent to constructivism, but active instructional methods do not always lead to active learning, and passive methods do not always lead to passive learning (Mayer, 2009).

Recently, Chi (2009) outlined the theoretical and behavioral differences between learning tasks that require the learner to be active and learning tasks that require the learner to be constructive, and she emphasized that the two are not one in the same. Although a meta-analysis of Chi's claims would be optimal to support her outline, she nonetheless has provided tentative explanations that are useful fodder and seemingly in agreement to some extent with the points of Mayer (2004). She explained that although activities requiring hands-on active participation from learners guarantee a level of engagement greater than passive reception of information, these activities do not guarantee that learners will be engaged to the extent necessary to make sense of the materials for themselves. From Chi's perspective, learning activities entailing true constructivism should require learners not only to engage in the learning task (e.g., manipulate objects or paraphrase) but also to construct ideas that surpass the presented information (e.g., to elaborate, predict, reflect). Chi's emphasis that constructivism should require learners to achieve these higher order objectives - similar to those outlined by Fletcher (2009) that include analysis, evaluative abilities, and creativity-illustrates that the objectives of constructivism are at least, in part, present within the learning activity itself.

Perhaps the completely unguided discovery activities objected to by Mayer (2004) were too ambiguous to allow learners to transcend the mere activity and to reach the level of constructivism intended. Through more guided tasks, the learner is liberated potentially from high demands on working memory and executive functioning abilities (Chi, 2009; Kirschner et al., 2006; Mayer, 2003; Rittle-Johnson, 2006; Sweller, 1988; Sweller et al., 2007) and can therefore direct his/her efforts toward more creative processes (e.g., inference, integration, and reorganization) as outlined by both Chi (2009) and Fletcher (2009). Our finding that generation is not an optimal form of enhanced discovery may illustrate this claim. The generation conditions required learners to generate rules, strategies, or images or to answer questions about the information, but there was little consistency in the extent to which learners had to go beyond the presented information to do so. Of the three types of enhanced discovery, generation required the least engagement of learners with respect to the types of activities that Chi identified as constructive.

The finding that enhanced forms of discovery are superior to unassisted forms also calls into question ecological perspectives of learning inherent within discovery pedagogy and perhaps constructivism more generally. Although it seems reasonable to expect learners to be able to construct their own understandings with minimal assistance because they do so on a daily basis in the context of everyday activities, perhaps the content and context of formal education are extraordinary (Geary, 2008) and consequently require more assistance to arrive at accurate constructions, understandings, and solutions (Sweller et al., 2007). It is also possible that people often learn what they do within daily life activities through forms of guided participation (Rogoff, 1990). 


\section{The Potential of Teaching Discovery}

In light of the previous discussion of Mayer (2004) and Chi (2009), we should return to the possibility that it might serve educators and students alike to spend time learning the procedures of discovery (Ausubel, 1964; Bielaczyc, Pirolli, \& Brown, 1995; Bruer, 1993; Dewey, 1910; Karpov \& Haywood, 1998; King, 1991; Kozulin, 1995; Kuhn, Black, Keselman, \& Kaplan, 2000). Teaching learners first to be discoverers (e.g., how to navigate the problem solving space, use limited working memory capacities efficiently, and attend to relevant information) could prepare them (Bruner, 1961) for active learning demands, as outlined by Chi, and perhaps provide some of the needed curricular focus and necessary structure to discovery tasks, as emphasized by Mayer (2004). Furthermore, by having learners better familiarized with the processes of discovery, the cognitive load demands (Kirschner et al., 2006; Rittle-Johnson, 2006; Sweller, 1988) might be reduced. Consequently, this might allow learners to engage with the learning tasks not only in active ways but also constructively (i.e., in the ways outlined by Chi, 2009) to allow them to go beyond the presented information. Bruner (1961, p. 26) emphasized that discovery encourages learners to be constructivists and that practice in discovering teaches the learner how best to acquire information to make it more readily available. Again, Bruner implied that the act of discovering is one that requires practice to be of value.

Bruner (1961) also warned that the learner's mind has to be prepared for discovery. The preparation that Bruner emphasized was not merely an existing knowledge base regarding the domain of study; he also emphasized that learning by discovery does not necessarily involve the acquisition of new information. Bruner claimed that discovery was more often the result of a learner gaining insights that transform his/her knowledge base through new ways of organizing the previously learned information. Furthermore, the prepared mind for Bruner was one with experience in discovery itself:

It goes without saying that, left to himself, the child will go about discovering things for himself within limits. It also goes without saying that there are certain forms of child rearing, certain home atmospheres that lead some children to be their own discoverers more than other children. (Bruner, 1961, p. 22)

Bruner (1961), like Vygotsky (1962), suggested that the narrative of teaching is a conversation that is appropriated by the learner who can subsequently use that narrative to teach himself/herself. Bruner emphasized that opportunities for discovery might facilitate this process. Consequently, it seems reasonable to conclude that discovery might itself be a scripted tool (i.e., a narrative) for making sense of materials on one's own (Arievitch \& Stetsenko, 2000; Kozulin, 1995; Stetsenko \& Arievitch, 2002; Wertsch, 1981). The steps and procedures of that script are not innate to the learner but need to be presented by teachers or parents, as emphasized by Bruner, because they are part of a culture (e.g., the culture of formal education). Thus, if learning through discovery is superior to other forms of instruction, then it might serve educators and students alike to spend time learning the procedures of discovery (Ausubel, 1964; Bielaczyc et al., 1995; Bruer, 1993; Dewey, 1910; Karpov \& Haywood, 1998; King, 1991; Kozulin, 1995; Kuhn et al., 2000). Generally, teaching the procedures of discovery to learners might provide some of the needed curricular focus and necessary structure to discovery instructional methods (concerns raised by Mayer, 2004). It might also reduce the cognitive demands of discovery learning tasks and make such methods more easily employed (a concern raised by Kirschner et al., 2006; Sweller et al., 2007).

Although we have suggested teaching learners how to discover, we do not mean to imply that we have arrived at some oversimplified strategy for discovery that can bridge all domains or learning tasks. On the contrary, directly instructing learners on problem-solving skills, analogies, and other cognitive processes should not be expected to lead learners to generalize those skills to all other areas of learning (Klahr, 2009; Sweller et al., 2007; Wise \& O’Neill, 2009). However, providing ample opportunities for learners to discover when and where those processes are appropriate could lead learners to such discovery-based constructivism only after those processes have been taught directly within the contexts of their appropriate domains.

More generally, teaching students how be constructive learners might begin with more basic preparation. Perhaps many learners are not prepared for such activities and educational reform needs to focus first at the level of reading comprehension to teach students how to make sense of new information (Herman \& Gomez, 2009) because domain-relevant information might be essential for successful construction of novel understandings during instruction, particularly in ill-structured domains (Rosenshine, 2009; Spiro \& DeSchryver, 2009). Herman and Gomez (2009, p. 70) have outlined several reading support tools designed to help students understand science texts in meaningful and useful ways. Although these tools need first to be taught explicitly, they could provide self-guidance while reading science texts thereafter. Perhaps similar reading support tools need to be developed for other texts as well so that students can come to view textbooks as helpful resources within their environments that they are able to interact with in meaningful ways to reach objectives, the definition of learning as proposed by Gresalfi and Lester (2009). These tools could establish foundations for learning that might not be readily generalizable from the moment that they are mastered but can be after practice, after experience in different contexts, and in the presence of scaffolding and feedback (Wise \& O'Neill, 2009).

\section{Conclusion}

Overall, the effects of unassisted-discovery tasks seem limited, whereas enhanced-discovery tasks requiring learners to be actively engaged and constructive seem optimal. On the basis of the current analyses, optimal approaches should include at least one of the following: (a) guided tasks that have scaffolding in place to assist learners, (b) tasks requiring learners to explain their own ideas and ensuring that these ideas are accurate by providing timely feedback, or (c) tasks that provide worked examples of how to succeed in the task. Opportunities for constructive learning might not present themselves when learners are left unassisted. Perhaps the findings of these meta-analyses can help to move the debate away from issues of unassisted forms of discovery and toward a fruitful discussion and consequent empirical investigations of how scaffolding is best implemented, how to provide feedback in classroom settings, how to create worked examples for varieties of content, and when during the learning task direct forms of instruction should be provided. 


\section{References}

References marked with an asterisk indicate studies included in the meta-analysis.

*Alibali, M. W. (1999). How children change their minds: Strategy change can be gradual or abrupt. Developmental Psychology, 35, 127-145. doi:10.1037/0012-1649.35.1.127

*Amsterlaw, J., \& Wellman, H. M. (2006). Theories of mind in transition: A microgenetic study of the development of false belief understanding. Journal of Cognition and Development, 7, 139-172. doi:10.1207/ s15327647jcd0702_1

*Anastasiow, N. J., Sibley, S. A., Leonhardt, T. M., \& Borich, G. D. (1970). A comparison of guided discovery, discovery and didactic teaching of math to kindergarten poverty children. American Educational Research Journal, 7, 493-510.

*Andrews, J. D. W. (1984). Discovery and expository learning compared: Their effects on independent and dependent students. Journal of Educational Research, 78, 80-89.

Arievitch, I. M., \& Stetsenko, A. (2000). The quality of cultural tools and cognitive development: Gal'perin's perspective and its implications. Human Development, 43, 69-92. doi:10.1159/000022661

Ausubel, D. P. (1964). Some psychological and educational limitations of learning by discovery. The Arithmetic Teacher, 11, 290-302.

*Bannert, M. (2000). The effects of training wheels and self-learning materials in software training. Journal of Computer Assisted Learning, 16, 336-346. doi:10.1046/j.1365-2729.2000.00146.x

*Belcastro, F. P. (1966). Relative effectiveness of the inductive and deductive methods of programming algebra. Journal of Experimental Education, 34, 77-82.

Bertsch, S., Pesta, B. J., Wiscott, R., \& McDaniel, M. A. (2007). The generation effect: A meta-analytic review. Memory \& Cognition, 35, 201-210.

*Bielaczyc, K., Pirolli, P. L., \& Brown, A. L. (1995). Training in selfexplanation and self-regulation strategies: Investigating the effects of knowledge acquisition activities on problem solving. Cognition and Instruction, 13, 221-252. doi:10.1207/s1532690xci1302_3

*Bluhm, W. J. (1979). The effects of science process skill instruction on preservice elementary teachers' knowledge of, ability to use, and ability to sequence science process skills. Journal of Research in Science Teaching, 16, 427-432. doi:10.1002/tea.3660160509

*Bobis, J., Sweller, J., \& Cooper, M. (1994). Demands imposed on primary-school students by geometric models. Contemporary Educational Psychology, 19, 108-117. doi:10.1006/ceps.1994.1010

Bok, D. (2006). Our underachieving colleges: A candid look at how much students learn and why they should be learning more. Princeton, NJ: Princeton University Press

Borenstein, M., Hedges, L., Higgins, J., \& Rothstein, H. (2005). Comprehensive Meta-Analysis Version 2. Englewood, NJ: Biostat.

*Bowyer, J. B., \& Linn, M. C. (1978). Effectiveness of the science curriculum improvement study in teaching scientific literacy. Journal of Research in Science Teaching, 15, 209-219. doi:10.1002/ tea.3660150304

*Bransford, J. D., \& Johnson, M. K. (1972). Contextual prerequisites for understanding: Some investigations of comprehension and recall. Journal of Verbal Learning and Verbal Behavior, 11, 717-726. doi:10.1016/ S0022-5371(72)80006-9

*Brant, G., Hooper, E., \& Sugrue, B. (1991). Which comes first the simulation or the lecture? Journal of Educational Computing Research, 7. 469-481.

*Brown, A. L., Kane, M. J., \& Long, C. (1989). Analogical transfer in young children: Analogies as tools for communication and exposition. Applied Cognitive Psychology, 3, 275-293. doi:10.1002/ acp. 2350030402
Bruer, J. T. (1993). Schools for thought: A science of learning in the classroom. Cambridge, MA: MIT Press.

Bruner, J. S. (1961). The act of discovery. Harvard Educational Review, 31, 21-32.

*Butler, C., Pine, K., \& Messer, D. J. (2006, September). Conceptually and procedurally based teaching in relation to children's understanding of cardinality. Paper presented at the British Psychological Society Developmental Section Conference, Royal Holloway University of London, Egham, Surrey.

*Cantor, G. N., Dunlap, L. L., \& Rettie, C. S. (1982). Effects of reception and discovery instruction on kindergarteners' performance on probability tasks. American Educational Research Journal, 19, 453-463.

*Carroll, W. M. (1994). Using worked examples as an instructional support in the algebra classroom. Journal of Educational Psychology, 86, 360367. doi:10.1037/0022-0663.86.3.360

Case, R. (1998). The development of conceptual structures. In D. Kuhn \& R. S. Siegler (Eds.), Handbook of child psychology: Cognition, perception, and language (Vol. 2, pp. 745-800). New York, NY: Wiley.

Chandler, P., \& Sweller, J. (1991). Cognitive load theory and the format of instruction. Cognition and Instruction, 8, 293-332. doi:10.1207/ s1532690xci0804_2

*Charney, D., Reder, L., \& Kusbit, G. W. (1990). Goal setting and procedure selection in acquiring computer skills: A comparison of tutorials, problem solving, and learner exploration. Cognition and Instruction, 7, 323-342. doi:10.1207/s1532690xci0704_3

*Chen, Z., \& Klahr, D. (1999). All other things being equal: Acquisition and transfer of the control of variables strategy. Child Development, 70, 1098-1120. doi:10.1111/1467-8624.00081

Chi, M. T. H. (2009). Active-constructive-interactive: A conceptual framework for differentiating learning activities. Topics in Cognitive Science, 1, 73-105. doi:10.1111/j.1756-8765.2008.01005.x

*Chi, M. T. H., de Leeuw, N., Chiu, M., \& LaVancher, C. (1994). Eliciting self-explanations improves understanding. Cognitive Science, 18, 439477.

Clark, R. E. (2009). How much and what type of guidance is optimal for learning from instruction? In S. Tobias \& T. M. Duffy (Eds.), Constructivist theory applied to instruction: Success or failure? (pp. 158-183). New York, NY: Taylor \& Francis.

Cohen, J. (1988). Statistical power analysis for the behavioral sciences (2nd ed.). Hillsdale, NJ: Erlbaum.

*Coleman, E. B., Brown, A. L., \& Rivkin, I. D. (1997). The effect of instructional explanations on learning from scientific texts. The Journal of the Learning Sciences, 6, 347-365. doi:10.1207/s15327809j1s0604_1

*Craig, R. C. (1965). Discovery, task completion, and the assignment as factors in motivation. American Educational Research Journal, 2, 217 222.

*Crowley, K., \& Siegler, R. S. (1999). Explanation and generalization in young children's strategy learning. Child Development, 70, 304-316. doi:10.1111/1467-8624.00023

*Danner, F. W., \& Day, M. C. (1977). Eliciting formal operations. Child Development, 48, 1600-1606. doi:10.2307/1128524

*Debowski, S., Wood, R. E., \& Bandura, A. (2001). Impact of guided exploration and enactive exploration on self-regulatory mechanisms and information acquisition through electronic search. Journal of Applied Psychology, 86, 1129-1141. doi:10.1037/0021-9010.86.6.1129

*Denson, D. W. (1986). The relationships between cognitive styles, method of instruction, knowledge, and process skills of college chemistry students (Unpublished doctoral dissertation, University Microfilms No. 87-05059). University of Southern Mississippi, Hattiesburg, MS.

*Destrebecqz, A. (2004). The effect of explicit knowledge on sequence learning: A graded account. Psychologica Belgica, 44, 217-247.

Dewey, J. (1910). How we think. Boston, MA: D. C. Heath. doi:10.1037/ 10903-000

Duffy, T. M. (2009). Building line of communication and a research 
agenda. In S. Tobias \& T. M. Duffy (Eds.), Constructivist theory applied to instruction: Success or failure? (pp. 351-367). New York, NY: Taylor \& Francis.

*Elias, M. J., \& Allen, G. J. (1991). A comparison of instructional methods for delivering a preventive social competence/social decision making program to at risk, average, and competent students. School Psychology Quarterly, 6, 251-272. doi:10.1037/h0088819

*Elshout, J. J., \& Veenman, M. V. J. (1992). Relation between intellectual ability and working method as predictors of learning. Journal of Educational Research, 85, 134-143.

*Fender, J. G., \& Crowley, K. (2007). How parent explanation changes what children learn from everyday scientific thinking. Journal of Applied Developmental Psychology, 28, 189-210. doi:10.1016/j .appdev.2007.02.007

Flavell, J. H. (2000). Development of children's knowledge about the mental world. International Journal of Behavioral Development, 24, 15-23. doi:10.1080/016502500383421

Fletcher, J. D. (2009). From behaviorism to constructivism. In S. Tobias \& T. M. Duffy (Eds.), Constructivist theory applied to instruction: Success or failure? (pp. 242-263). New York, NY: Taylor \& Francis.

*Foos, P. W., Mora, J. J., \& Tkacz, S. (1994). Student study techniques and the generation effect. Journal of Educational Psychology, 86, 567-576. doi:10.1037/0022-0663.86.4.567

*Gagné, R. M., \& Brown, L. T. (1961). Some factors in the programming of conceptual learning. Journal of Experimental Psychology, 62, 313321. doi: $10.1037 / \mathrm{h} 0049210$

Geary, D. C. (2008). Whither evolutionary educational psychology? Educational Psychologist, 43, 217-226. doi:10.1080/00461520802392240

*Ginns, P., Chandler, P., \& Sweller, J. (2003). When imagining information is effective. Contemporary Educational Psychology, 28, 229-251. doi:10.1016/S0361-476X(02)00016-4

*Grandgenett, N., \& Thompson, A. (1991). Effects of guided programming instruction on the transfer of analogical reasoning. Journal of Educational Computing Research, 7, 293-308.

*Greenockle, K. M., \& Lee, A. (1991). Comparison of guided and discovery learning strategies. Perceptual and Motor Skills, 72, 1127-1130. doi:10.2466/PMS.72.4.1127-1130

Gresalfi, M. S., \& Lester, F. (2009). What's worth knowing in mathematics? In S. Tobias \& T. M. Duffy (Eds.), Constructivist theory applied to instruction: Success or failure? (pp. 264-290). New York, NY: Taylor $\&$ Francis.

*Guthrie, J. T. (1967). Expository instruction versus a discovery method. Journal of Educational Psychology, 58, 45-49. doi:10.1037/h0024112

Hake, R. R. (2004, August). Direct instruction suffers a setback in California-Or does it? Paper presented at the 129th National AAPT Meeting, Sacramento, CA

*Hendrickson, G., \& Schroeder, W. H. (1941). Transfer of training in learning to hit a submerged target. Journal of Educational Psychology, 32, 205-213. doi:10.1037/h0056643

*Hendrix, G. (1947). A new clue to transfer of training. The Elementary School Journal, 48, 197-208. doi:10.1086/458927

Herman, P., \& Gomez, L. M. (2009). Taking guided learning theory to school. In S. Tobias \& T. M. Duffy (Eds.), Constructivist theory applied to instruction: Success or failure? (pp. 62-81). New York, NY: Taylor $\&$ Francis.

*Hiebert, J., \& Wearne, D. (1993). Instructional tasks, classroom discourse, and students' learning in second-grade arithmetic. American Educational Research Journal, 30, 393-425.

*Hirsch, C. R. (1977). The effects of guided discovery and individualized instructional packages on initial learning, transfer, and retention in second-year algebra. Journal for Research in Mathematics Education, 8, 359-368. doi:10.2307/748407

Hmelo-Silver, C. E., Duncan, R. G., \& Chinn, C. A. (2007). Scaffolding and achievement in problem-based and inquiry learning: A response to
Kirschner, Sweller, and Clark (2006). Educational Psychologist, 42 , 99-107.

*Hodges, N. J., \& Lee, T. D. (1999). The role of augmented information prior to learning a bimanual visual-motor coordination task: Do instructions of the movement pattern facilitate learning relative to discovery learning? British Journal of Psychology, 90, 389-403. doi:10.1348/ 000712699161486

*Howe, C., McWilliam, D., \& Cross, G. (2005). Chance favours only the prepared mind: Incubation and the delayed effects of peer collaboration British Journal of Psychology, 96, 67-93. doi:10.1348/ $000712604 \mathrm{X} 15527$

*Jackson, A. C., Fletcher, B. C., \& Messer, D. J. (1992). When talking doesn't help: An investigation of microcomputer-based group problem solving. Learning and Instruction, 2, 185-197. doi:10.1016/09594752(92)90008-A

*Jiménez, L., Méndez, C., \& Cleeremans, A. (1996). Comparing direct and indirect measures of sequence learning. Journal of Experimental Psychology: Learning, Memory, and Cognition, 22, 948-969. doi:10.1037/ 0278-7393.22.4.948

Johnson, B. (1989). DSTAT: Software for the meta-analytic review of research literature. Hillsdale, $\mathrm{NJ}$ : Erlbaum.

Johnson, B. (1993). DSTAT 1.10 software for the meta-analytic review of research literature: Upgrade documentation. Hillsdale, NJ: Erlbaum.

Kagan, J. (1966). Learning, attention, and the issue of discovery. In L. S. Shulman \& E. R. Keislar (Eds.), Learning by discovery: A critical appraisal (pp. 151-161). Chicago, IL: Rand McNally.

*Kalyuga, S., Chandler, P., \& Sweller, J. (2001). Learner experience and efficiency of instructional guidance. Educational Psychology, 21, 5-23. doi:10.1080/01443410124681

*Kalyuga, S., Chandler, P., Tuovinen, J., \& Sweller, J. (2001). When problem solving is superior to studying worked examples. Journal of Educational Psychology, 93, 579-588. doi:10.1037/0022-0663.93.3.579

*Kamii, C., \& Dominick, A. (1997). To teach or not to teach algorithms. Journal of Mathematical Behavior, 16, 51-61. doi:10.1016/S07323123(97)90007-9

Karpov, Y. V., \& Haywood, H. C. (1998). Two ways to elaborate Vygotsky's concept of mediation: Implications for instruction. American Psychologist, 53, 27-36. doi:10.1037/0003-066X.53.1.27

*Kastens, K. A., \& Liben, L. S. (2007). Eliciting self-explanations improves children's performance on a field-based map skills task. Cognition and Instruction, 25, 45-74.

*Kelemen, D. (2003). British and American children's preferences for teleo-functional explanations of the natural world. Cognition, 88, 201221. doi:10.1016/S0010-0277(03)00024-6

Kendler, H. H. (1966). Reflections on the conference. In L. S. Shulman \& E. R. Keislar (Eds.), Learning by discovery: A critical appraisal (pp. 171-176). Chicago, IL: Rand McNally.

*Kersh, B. Y. (1958). The adequacy of "meaning" as an explanation for the superiority of learning by independent discovery. Journal of Educational Psychology, 49, 282-292. doi:10.1037/h0044500

*Kersh, B. Y. (1962). The motivating effect of learning by directed discovery. Journal of Educational Psychology, 53, 65-71. doi:10.1037/ h0044269

*King, A. (1991). Effects of training in strategic questioning on children's problem-solving performance. Journal of Educational Psychology, 83, 307-317. doi:10.1037/0022-0663.83.3.307

Kintsch, W. (2009). Learning and constructivism. In S. Tobias \& T. M. Duffy (Eds.), Constructivist theory applied to instruction: Success or failure? (pp. 223-241). New York, NY: Taylor \& Francis.

Kirschner, P. A., Sweller, J., \& Clark, R. E. (2006). Why minimal guidance during instruction does not work: An analysis of the failure of constructivist, discovery, problem-based, experiential, and inquiry-based teaching. Educational Psychologist, 41, 75-86. doi: 10.1207/s15326985ep4102_1 
*Kittell, J. E. (1957). An experimental study of the effect of external direction during learning on transfer and retention of principles. Journal of Educational Psychology, 48, 391-405. doi:10.1037/h0046792

Klahr, D. (2009). "To every thing there is a season, and a time to every purpose under the heavens": What about direct instruction? In S. Tobias \& T. M. Duffy (Eds.), Constructivist theory applied to instruction: Success or failure? (pp. 291-310). New York, NY: Taylor \& Francis.

*Klahr, D., \& Nigam, M. (2004). The equivalence of learning paths in early science instruction: Effects of direct instruction and discovery learning. Psychological Science, 15, 661-667. doi:10.1111/j.09567976.2004.00737.x

Kozulin, A. (1995). The learning process: Vygotsky's theory in the mirror of its interpretations. School Psychology International, 16, 117-129. doi: $10.1177 / 0143034395162003$

Kuhn, D. (2007). Is direct instruction an answer to the right question? Educational Psychologist, 42, 109-113.

*Kuhn, D., Black, J., Keselman, A., \& Kaplan, D. (2000). The development of cognitive skills to support inquiry learning. Cognition and Instruction, 18, 495-523. doi:10.1207/S1532690XCI1804_3

Kuhn, D., \& Dean, D. (2004). Connecting scientific reasoning and causal inference. Journal of Cognition and Development, 5, 261-288. doi: 10.1207/s15327647jcd0502_5

*Kuhn, D., \& Dean, D. (2005). Is developing scientific thinking all about learning to control variables? Psychological Science, 16, 866-870. doi:10.1111/j.1467-9280.2005.01628.x

*Lamborn, S. D., Fischer, K. W., \& Pipp, S. (1994). Constructive criticism and social lies: A developmental sequence for understanding honesty and kindness in social interactions. Developmental Psychology, 30, 495-508. doi:10.1037/0012-1649.30.4.495

*Lawson, A. E., \& Wollman, W. T. (1976). Encouraging the transition from concrete to formal cognitive functioning-An experiment. Journal of Research in Science Teaching, 13, 413-430. doi:10.1002/ tea.3660130505

*Lazonder, A. W., \& van der Meij, H. (1993). The minimal manual: Is less really more? International Journal of Man-Machine Studies, 39, 729752. doi:10.1006/imms.1993.1081

*Lazonder, A. W., \& van der Meij, H. (1994). Effect of error information in tutorial documentation. Interacting with Computers, 6, 23-40. doi: 10.1016/0953-5438(94)90003-5

*Lazonder, A. W., \& van der Meij, H. (1995). Error-information in tutorial documentation: Supporting users' errors to facilitate initial skill learning. International Journal of Human-Computer Studies, 42, 185-206. doi:10.1006/ijhc.1995.1009

*Lee, M. O. C., \& Thompson, A. (1997). Guided instruction in LOGO programming and the development of cognitive monitoring strategies among college students. Journal of Educational Computing Research, $16,125-144$.

*Leutner, D. (1993). Guided discovery learning with computer-based simulation games: Effects of adaptive and non-adaptive instructional support. Learning and Instruction, 3, 113-132. doi:10.1016/09594752(93)90011-N

Mayer, R. E. (2003). Learning and instruction. Upper Saddle River, NJ: Prentice Hall.

Mayer, R. E. (2004). Should there be a three-strikes rule against pure discovery learning? The case for guided methods of instruction. American Psychologist, 59, 14-19. doi:10.1037/0003-066X.59.1.14

Mayer, R. E. (2009). Constructivism as a theory of learning versus constructivism as a prescription for instruction. In S. Tobias \& T. M. Duffy (Eds.), Constructivist theory applied to instruction: Success or failure? (pp. 184-200). New York, NY: Taylor \& Francis.

*McDaniel, M. A., \& Pressley, P. (1984). Putting the keyword method in context. Journal of Educational Psychology, 76, 598-609. doi:10.1037/ 0022-0663.76.4.598

*McDaniel, M. A., \& Schlager, M. S. (1990). Discovery learning and transfer of problem-solving skills. Cognition and Instruction, 7, 129 159. doi:10.1207/s1532690xci0702_3

*Messer, D. J., Joiner, R., Loveridge, N., Light, P., \& Littleton, K. (1993). Influences on the effectiveness of peer interaction: Children's level of cognitive development and the relative ability of partners. Social Development, 2, 279-294. doi:10.1111/j.1467-9507.1993.tb00018.x

*Messer, D. J., Mohamedali, M. H., \& Fletcher, B. (1996). Using computers to help pupils tell the time, is feedback necessary? Educational Psychology, 16, 281-296. doi:10.1080/0144341960160305

*Messer, D. J., Norgate, S., Joiner, R., Littleton, K., \& Light, P. (1996). Development without learning? Educational Psychology, 16, 5-19. doi: $10.1080 / 0144341960160101$

*Morton, J. B., Trehub, S. E., \& Zelazo, P. D. (2003). Sources of inflexibility in 6-year-olds' understanding of emotion in speech. Child Development, 74, 1857-1868. doi:10.1046/j.1467-8624.2003.00642.x

*Murphy, N., \& Messer, D. (2000). Differential benefits from scaffolding and children working alone. Educational Psychology, 20, 17-31. doi: $10.1080 / 014434100110353$

*Mwangi, W., \& Sweller, J. (1998). Learning to solve compare word problems: The effect of example format and generating selfexplanations. Cognition and Instruction, 16, 173-199. doi:10.1207/ s1532690xci1602_2

*Nadolski, R. J., Kirschner, P. A., \& Van Merriënboer, J. J. G. (2005). Optimizing the number of steps in learning tasks for complex skills. British Journal of Educational Psychology, 75, 223-237. doi:10.1348/ 000709904X22403

*O'Brien, T. C., \& Shapiro, B. J. (1977). Number patterns: Discovery versus reception learning. Journal for Research in Mathematics Education, 8, 83-87. doi:10.2307/748536

*Öhrn, M. A. K., Van Oostrom, J. H., \& Van Meurs, W. L. (1997). A comparison of traditional textbook and interactive computer learning of neuromuscular block. Anesthesia \& Analgesia, 84, 657-661. doi: 10.1097/00000539-199703000-00035

*Olander, H. T., \& Robertson, H. C. (1973). The effectiveness of discovery and expository methods in the teaching of fourth-grade mathematics. Journal for Research in Mathematics Education, 4, 33-44. doi:10.2307/ 749022

*Paas, F. G. W. C. (1992). Training strategies for attaining transfer of problem-solving skill in statistics: A cognitive-load approach. Journal of Educational Psychology, 84, 429-434. doi:10.1037/0022-0663 84.4.429

Paas, F. G. W. C., Renkl, A., \& Sweller, J. (2003). Cognitive load theory and instructional design: Recent developments. Educational Psychologist, 38, 1-4. doi:10.1207/S15326985EP3801_1

*Paas, F. G. W. C., \& Van Merriënboer, J. J. G. (1994). Variability of worked examples and transfer of geometrical problem-solving skills: A cognitive-load approach. Journal of Educational Psychology, 86, 122133. doi:10.1037/0022-0663.86.1.122

*Pany, D., \& Jenkins, J. R. (1978). Learning word meanings: A comparison of instructional procedures. Learning Disability Quarterly, 1, 2132. doi: $10.2307 / 1510304$

Pea, R. D. (2004). The social and technological dimensions of scaffolding and related theoretical concepts for learning, education, and human activity. The Journal of the Learning Sciences, 13, 423-451. doi: 10.1207/s15327809j1s1303_6

*Peters, D. L. (1970). Discovery learning in kindergarten mathematics. Journal for Research in Mathematics Education, 1, 76-87. doi:10.2307/ 748854

Piaget, J. (1952). The origins of intelligence in children (M. Cook, Trans.). New York, NY: International Universities Press. doi:10.1037/11494-000

Piaget, J. (1965). Science of education and the psychology of the child. In H. E. Gruber \& J. J. Voneche (Eds.), The essential Piaget (pp. 695-725). New York, NY: Basic Books.

Piaget, J. (1980). The psychogenesis of knowledge and its epistemological 
significance. In M. Piattelli-Palmarini (Ed.), Language and learning (pp. 23-54). Cambridge, MA: Harvard University Press.

*Pillay, H. K. (1994). Cognitive load and mental rotation: Structuring orthographic projection for learning and problem solving. Instructional Science, 22, 91-113. doi:10.1007/BF00892159

*Pillow, B. H., Mash, C., Aloian, S., \& Hill, V. (2002). Facilitating children's understanding of misinterpretation: Explanatory efforts and improvements in perspective taking. Journal of Genetic Psychology, 163, 133-148. doi:10.1080/00221320209598673

*Pine, K. J., \& Messer, D. J. (2000). The effect of explaining another's actions on children's implicit theories of balance. Cognition and Instruction, 18, 35-51. doi:10.1207/S1532690XCI1801_02

*Pine, K. J., Messer, D. J., \& Godfrey, K. (1999). The teachability of children with naïve theories: An exploration of the effects of two teaching methods. British Journal of Educational Psychology, 69, 201211. doi:10.1348/000709999157671

*Quilici, J. L., \& Mayer, R. E. (1996). Role of examples in how students learn to categorize statistics word problems. Journal of Educational Psychology, 88, 144-161. doi:10.1037/0022-0663.88.1.144

*Radziszewska, B., \& Rogoff, B. (1991). Children's guided participation in planning imaginary errands with skilled adult or peer partners. Developmental Psychology, 27, 381-389. doi:10.1037/0012-1649.27.3.381

*Rappolt-Schlichtmann, G., Tenenbaum, H. R., Koepke, M. F., \& Fischer, K. (2007). Transient and robust knowledge: Contextual support and the dynamics of children's reasoning about density. Mind, Brain, and Education, 1, 98-108. doi:10.1111/j.1751-228X.2007.00010.x

*Ray, W. E. (1961). Pupil discovery vs. direct instruction. Journal of Experimental Education, 29, 271-280.

*Reid, D. J., Zhang, J., \& Chen, Q. (2003). Supporting scientific discovery learning in a simulation environment. Journal of Computer Assisted Learning, 19, 9-20. doi:10.1046/j.0266-4909.2003.00002.x

*Reinking, D., \& Rickman, S. S. (1990). The effects of computer-mediated texts on the vocabulary learning and comprehension of intermediategrade readers. Journal of Reading Behavior, 22, 395-411.

*Rieber, L. P., \& Parmley, M. W. (1995). To teach or not to teach? Comparing the use of computer-based simulations in deductive versus inductive approaches to learning with adults in science. Journal of Educational Computing Research, 13, 359-374.

*Rittle-Johnson, B. (2006). Promoting transfer: Effects of self-explanation and direct instruction. Child Development, 77, 1-15. doi:10.1111/j.14678624.2006.00852.x

*Rittle-Johnson, B., Saylor, M., \& Swygert, K. E. (2008). Learning from explaining: Does it matter if mom is listening? Journal of Experimental Child Psychology, 100, 215-224. doi:10.1016/j.jecp.2007.10.002

Rogoff, B. (1990). Apprenticeship in thinking: Cognitive development in social context. New York, NY: Random.

Rosenshine, B. (2009). The empirical support for direct instruction. In S. Tobias \& T. M. Duffy (Eds.), Constructivist theory applied to instruction: Success or failure? (pp. 201-220). New York, NY: Taylor \& Francis.

*Salmon, K., Yao, J., Berntsen, O., \& Pipe, M. (2007). Does providing props during preparation help children to remember a novel event? Journal of Experimental Child Psychology, 97, 99-116. doi:10.1016/ j.jecp.2007.01.001

*Scandura, J. M. (1964). An analysis of exposition and discovery modes of problem solving instruction. Journal of Experimental Education, 33, 149-159.

Schmidt, H. G., Loyens, S. M. M., van Gog, T., \& Paas, F. (2007). Problem-based learning is compatible with human cognitive architecture: Commentary on Kirschner, Sweller, and Clark (2006). Educational Psychologist, 42, 91-97.

Schwartz, D. L., \& Bransford, J. D. (1998). A time for telling. Cognition and Instruction, 16, 475-522. doi:10.1207/s1532690xci1604_4

Schwartz, D. L., Lindgren, R., \& Lewis, S. (2009). Constructivism in an age of non-constructivist assessments. In S. Tobias \& T. M. Duffy (Eds.), Constructivist theory applied to instruction: Success or failure? (pp. 34-61). New York, NY: Taylor \& Francis.

*Shore, W. J., \& Durso, F. T. (1990). Partial knowledge in vocabulary acquisition: General constraints and specific detail. Journal of Educational Psychology, 82, 315-318. doi:10.1037/0022-0663.82.2.315

*Shute, V. J., Glaser, R., \& Raghavan, K. (1989). Inference and discovery in an exploratory laboratory. In P. L. Ackerman, R. J. Sternberg, \& R. Glaser (Eds.), Learning and individual differences: Advances in theory and research (pp. 279-326). New York, NY: Freeman.

*Siegel, A. W., \& Corsini, D. A. (1969). Attentional differences in children's incidental learning. Journal of Educational Psychology, 60, 6570. doi:10.1037/h0026672

*Singer, R. N., \& Gaines, L. (1975). Effects of prompted and problemsolving approaches on learning and transfer of motor skills. American Educational Research Journal, 12, 395-403.

*Singer, R. N., \& Pease, D. (1978). Effect of guided vs. discovery learning strategies on initial motor task learning, transfer, and retention. Research Quarterly, 49, 206-217.

Slamecka, N. J., \& Graf, P. (1978). The generation effect: Delineation of a phenomenon. Journal of Experimental Psychology: Human Learning and Memory, 4, 592-604. doi:10.1037/0278-7393.4.6.592

Spiro, R. J., \& DeSchryver, M. (2009). Constructivism. In S. Tobias \& T. M. Duffy (Eds.), Constructivist theory applied to instruction: Success or failure? (pp. 106-123). New York, NY: Taylor \& Francis.

*Stark, R., Gruber, H., Renkl, A., \& Mandl, H. (1998). Instructional effects in complex learning: Do objective and subjective learning outcomes converge? Learning and Instruction, 8, 117-129. doi:10.1016/S09594752(97)00005-4

*Stark, R., Mandl, H., Gruber, H., \& Renkl, A. (2002). Conditions and effects of example elaboration. Learning and Instruction, 12, 39-60. doi:10.1016/S0959-4752(01)00015-9

Stetsenko, A., \& Arievitch, I. (2002). Teaching, learning and development: A post-Vygotskian perspective. In G. Wells \& G. Claxton (Eds.), Learning for life in the twenty-first century: Sociocultural perspectives on the future of education (pp. 84-96). London, England: Blackwell.

*Strand-Cary, M., \& Klahr, D. (2008). Developing elementary science skills: Instructional effectiveness and path independence. Cognitive Development, 23, 488-511. doi:10.1016/j.cogdev.2008.09.005

*Stull, A. T., \& Mayer, R. E. (2006, July). Three experimental comparisons of learner-generated versus author-provided graphic organizers. Poster presented at the 28th Annual Conference of the Cognitive Science Society, Vancouver, British Columbia, Canada.

*Sutherland, R., Pipe, M., Schick, K., Murray, J., \& Gobbo, C. (2003). Knowing in advance: The impact of prior event information on memory and event knowledge. Journal of Experimental Child Psychology, 84, 244-263. doi:10.1016/S0022-0965(03)00021-3

*Swaak, J., de Jong, T., \& Van Joolingen, W. R. (2004). The effects of discovery learning and expository instruction on the acquisition of definitional and intuitive knowledge. Journal of Computer Assisted Learning, 20, 225-234. doi:10.1111/j.1365-2729.2004.00092.x

*Swaak, J., Van Joolingen, W. R., \& De Jong, T. (1998). Supporting simulation-based learning: The effects of model progression and assignments on definitional and intuitive knowledge. Learning and Instruction, 8, 235-252. doi:10.1016/S0959-4752(98)00018-8

Sweller, J. (1988). Cognitive load during problem solving: Effects on learning. Cognitive Science, 12, 257-285. doi:10.1207/ s15516709 $\operatorname{cog} 1202 \_4$

Sweller, J. (1994). Cognitive load theory, learning difficulty, and instructional design. Learning and Instruction, 4, 295-312. doi:10.1016/09594752(94)90003-5

Sweller, J. (2009). What human cognitive architecture tells us about constructivism. In S. Tobias \& T. M. Duffy (Eds.), Constructivist theory 
applied to instruction: Success or failure? (pp. 127-143). New York, NY: Taylor \& Francis.

*Sweller, J., Chandler, P., Tierney, P., \& Cooper, M. (1990). Cognitive load as a factor in the structuring of technical material. Journal of Experimental Psychology: General, 119, 176-192. doi:10.1037/00963445.119.2.176

Sweller, J., Kirschner, P. A., \& Clark, R. E. (2007). Why minimally guided teaching techniques do not work: A reply to commentaries. Educational Psychologist, 42, 115-121.

*Tarmizi, R. A., \& Sweller, J. (1988). Guidance during mathematical problem solving. Journal of Educational Psychology, 80, 424-436. doi:10.1037/0022-0663.80.4.424

*Tenenbaum, H. R., Alfieri, L., Brooks, P. J., \& Dunne, G. (2008). The effects of explanatory conversations on children's emotion understanding. British Journal of Developmental Psychology, 26, 249-263. doi: $10.1348 / 026151007 \mathrm{X} 231057$

Tobias, S., \& Duffy, T. M. (Eds.). (2009). Constructivist theory applied to instruction: Success or failure? New York, NY: Taylor \& Francis.

*Trafton, J. G., \& Reiser, B. J. (1993). The contributions of studying examples and solving problems to skill acquisition. In The Proceedings of the 1993 Conference of the Cognitive Science Society (pp. 10171022). Hillsdale, NJ: Erlbaum.

*Tunteler, E., \& Resing, W. C. M. (2002). Spontaneous analogical transfer in 4-year-olds: A microgenetic study. Journal of Experimental Child Psychology, 83, 149-166. doi:10.1016/S0022-0965(02)00125-X

*Tuovinen, J. E., \& Sweller, J. (1999). A comparison of cognitive load associated with discovery learning and worked examples. Journal of Educational Psychology, 91, 334-341. doi:10.1037/0022-0663.91.2.334

*van der Meij, H., \& Lazonder, A. W. (1993). Assessment of the minimalist approach to computer user documentation. Interacting with Computers, 5, 355-370. doi:10.1016/0953-5438(93)90001-A

*van hout Wolters, B. H. A. M. (1990). Selecting and cueing key phrases in instructional texts. In H. Mandl, E. De Corte, N. Bennett, \& H. F. Friedrich (Eds.), Learning and instruction, European research in an international context: Vol. 2.2. Analysis of complex skills and complex knowledge domains (pp. 181-197). New York, NY: Pergamon Press.

*Veenman, M. V. J., Elshout, J. J., \& Busato, V. V. (1994). Metacognitive mediation in learning with computer-based simulations. Computers in Human Behavior, 10, 93-106. doi:10.1016/0747-5632(94)90031-0

*Vichitvejpaisal, P., Sitthikongsak, S., Preechakoon, B., Kraiprasit, K., Parakkamodom, S., Manon, C., \& Petcharatana, S. (2001). Does computer-assisted instruction really help to improve the learning process? Medical Education, 35, 983-989.

Vygotsky, L. (1962). Thought and language. Cambridge, MA: MIT Press. doi:10.1037/11193-000

*Ward, M., \& Sweller, J. (1990). Structuring effective worked examples. Cognition and Instruction, 7, 1-39. doi:10.1207/s1532690xci0701_1

Wertsch, J. (1981). The concepts of activity in Soviet psychology. Armonk, NY: Sharpe.

Wise, A. F., \& O’Neill, K. (2009). Beyond more versus less. In S. Tobias \& T. M. Duffy (Eds.), Constructivist theory applied to instruction: Success or failure? (pp. 82-105). New York, NY: Taylor \& Francis.

*Wittrock, M. C. (1963). Verbal stimuli in concept formation: Learning by discovery. Journal of Educational Psychology, 54, 183-190. doi: $10.1037 / \mathrm{h} 0043782$

*Worthen, B. R. (1968). A study of discovery and expository presentation: Implications for teaching. Journal of Teacher Education, 19, 223-242. doi: $10.1177 / 002248716801900215$

*Zacharia, Z., \& Anderson, O. R. (2003). The effects of an interactive computer-based simulation prior to performing a laboratory inquirybased experiment in students' conceptual understanding of physics. American Journal of Physiology, 71, 618-629. doi:10.1119/1.1566427

*Zhang, J., Chen, Q., Sun, Y., \& Reid, D. J. (2004). Triple scheme of learning support design for scientific discovery learning based on computer simulation: Experimental research. Journal of Computer Assisted Learning, 20, 269-282. doi:10.1111/j.1365-2729.2004.00062.x

*Zimmermann, M. J., \& Sassenrath, J. M. (1978). Improvement in arithmetic and reading and discovery learning in mathematics (SEED). Educational Research Quarterly, 3, 27-33.

Received October 21, 2009

Revision received July 28, 2010

Accepted July 28, 2010 